\title{
To Confirm or to Conform? Performance Goals as a Regulator of Conflict With More-Competent Others
}

\author{
Nicolas Sommet \\ Université de Lausanne
}

\author{
Céline Darnon \\ Université Blaise Pascal, Clermont Université, and Institut \\ Universitaire de France
}

Fabrizio Butera

Université de Lausanne

\begin{abstract}
Despite the fact that most competence-relevant settings are socially relevant settings, the interpersonal effects of achievement goals have been understudied. This is all the more surprising in the case of performance goals, for which self-competence is assessed using an other-referenced standard. In the present research, performance goals are conceived as a social tool for regulating interpersonal behaviors with more-competent others. In the confrontation with a more- (vs. equally) competent disagreeing partner, performance-approach goals (focus on approaching normative competence) should be associated with more-dominant behavior (i.e., competitive conflict regulation), whereas performance-avoidance goals (focus on avoiding normative incompetence) should be associated with more-submissive behavior (i.e., protective conflict regulation). Four studies give support to these predictions with self-reported conflict regulation measures (Studies 1 and 3) and evaluation of models associated with self-confirmation and compliance (Study 2) and conflict regulation behaviors (Study 4). Theoretical contributions to both the literature on achievement goals and that on socio-cognitive conflict, as well as practical implications for the issue of competence asymmetry in educational settings, are discussed.
\end{abstract}

Keywords: performance goals, relative competence, socio-cognitive conflict, interpersonal behavior regulation, self-evaluation threat

Most educational psychologists advocate the use of dynamic (i.e., based on interactions between learners) rather than static (i.e., based on instructions from educator to learners) learning systems (e.g., Johnson \& Johnson, 2009; Patrick, Kaplan, \& Ryan, 2011; Reyes, Brackett, Rivers, White, \& Salovey, 2012). Indeed, interventions designed to promote and structure social interactions between learners are regularly proposed in the literature, be they concerned with classrooms (e.g., Muis \& Duffy, 2013), small

This article was published Online First July 7, 2014.

Nicolas Sommet, Institut de Psychologie, Université de Lausanne. Céline Darnon, Laboratoire de Psychologie Sociale et Cognitive, Université Blaise Pascal; Department of Psychology, Clermont Université; and Institut Universitaire de France. Fabrizio Butera, Institut de Psychologie, Université de Lausanne.

This work was supported by the Swiss National Science Foundation and was part of Nicolas Sommet's doctoral thesis under the supervision of Fabrizio Butera. We wish to thank Vincent Pillaud, Caroline Pulfrey, Marijn Poortvliet, and Antonin Carrier for their helpful comments on this research; François Faure, the principal of the Lycée Professionnel Emmanuel Chabrier, as well as all the teachers and pupils who participated in Study 2; Simon Flandin, who put us in contact with this school; and the two assistants, Fallonne Marques and Loyse Haeller, for their help with recruitment of participants and data coding in Study 4.

Correspondence concerning this article should be addressed to Fabrizio Butera, Université de Lausanne - IP-SSP, Géopolis, CH 1015 - Lausanne, Switzerland. E-mail: fabrizio.butera@unil.ch groups (e.g., Ramani, Siegler, \& Hitti, 2012), or dyads (e.g., Buchs, Gilles, Dutrévis, \& Butera, 2011). Such dynamic learning systems may be effective in that they allow learners to interact with more-knowledgeable peers (Vygotsky, 1978) holding a different viewpoint (Mugny \& Doise, 1978; see also Fawcett \& Garton, 2005), thereby providing exposure to new knowledge. Yet, when facing a more-competent disagreeing other, learners often fail to engage in a coordinated and constructive interaction (Cohen \& Lotan, 1995), as the higher competence of the coactor may be perceived as a threat to self-evaluation (Muller \& Butera, 2007).

In such a confrontation, when do individuals ignore the other's viewpoint, sticking to their own, and when, instead, do they comply? Some attempts to provide a micro-level analysis of disagreeing processes with more-competent others have contributed to understanding why learners sometimes fail to coregulate their conversational space (Barron, 2003), but the motivational determinants of these processes have never been investigated. This neglect is surprising, because confrontation with more-competent others is a common situation, especially in educational settings (e.g., unequal-status interactions in classrooms; Cohen \& Lotan, 1995), and understanding the motivational determinants of its regulation may be of utmost importance to design facilitating interventions. The present research aims at addressing this issue. We argue that performance goals-namely, the desire to show competence in comparison with others-can function as a regulator of the specific interpersonal behavior, confirming one's own 
point of view or conforming to that of the more-competent other, displayed to cope with disagreement.

\section{Achievement Goals and Interpersonal Behaviors}

In competence-relevant settings, learners might adopt different achievement goals to regulate their behaviors (Elliot, 1999). Traditionally, scholars have distinguished two forms of achievement goals: mastery goals and performance goals (Dweck, 1975). The former goal is centered on the acquisition of competences, that is, progressing (or not declining) on a task, whereas the latter one is centered on the demonstration of the competences, that is, outperforming (or not being outperformed by) significant others.

Later, Elliot and Harackiewicz (1996) proposed that performance goals could be dichotomized into performance-approach goals (focused on attaining normative competence; i.e., related to the desire to perform better than others) and performanceavoidance goals (focused on avoiding normative incompetence; i.e., related to the desire not to perform worse than others). For instance, a student willing to reach the top three positions in his or her class would typically follow performance-approach goals, while another student, willing not to be below the class grade average, would follow performance-avoidance goals. ${ }^{1}$

The trichotomous framework of achievement goals has fueled nearly two decades of research, mainly focused on intrapersonallevel outcomes. For instance, in educational settings, achievement goals have proven to be robust predictors of academic performance (for a recent meta-analysis, see Van Yperen, Blaga, \& Postmes, 2014), intrinsic motivation (Dinger, Dickhäuser, Spinath, \& Steinmayr, 2013), or self-regulated learning strategies (Senko, Hama, \& Belmonte, 2013). However, most competence-relevant settings are also socially relevant settings (e.g., classrooms, learning groups, peer tutoring), and, as educational psychologists refined their paradigms over the years, they "bec[a]me increasingly aware that education [does] not take place in a social vacuum" (Husén, 1994, p. 5055). As a matter of fact, the quality of social interactions between learners (e.g., in social perspective taking, social cue processing, interpersonal trust) is indeed associated with academic accomplishment (for a review, see Wentzel, 2005), intrinsic motivation (Fraser \& Fisher, 1982), and self-regulated learning (Whitebread, Bingham, Grau, Pino Pasternak, \& Sangster, 2007).

Thus, social interactions are a core element in educational and learning processes, and it is therefore surprising that the interpersonal-level outcomes of achievement goals have remained largely understudied, and this in spite of the recurrent calls pinpointing the dearth of empirical research (Conroy, Elliot, \& Thrash, 2009; Darnon, Dompnier, \& Poortvliet, 2012; Kaplan, 2004; Liem, Lau, \& Nie, 2008; Poortvliet \& Darnon, 2010). Even more surprising is the lack of studies on the interpersonal effect of performance goals in particular. Indeed, performance goals involve an assessment of success and failure using an inter-personal standard (i.e., self-/other-performance comparison), which is less the case of mastery goals, associated with an intra-personal standard (i.e., past/present self-performance comparison; Elliot, 2005). Accordingly, performance-approach and performance-avoidance goals are associated with keen attention to others' level of competence (Elliot, 1999).

In line with this analysis, it has been noted that primary (Boissicat, Pansu, Bouffard, \& Cottin, 2012), secondary (Trautwein,
Lüdtke, Marsh, \& Nagy, 2009) and postsecondary (Sommet, Pulfrey, \& Butera, 2013) education is conducive to within-group social comparison, notably through the use of public and normative competence feedback (e.g., grades; Pulfrey, Darnon, \& Butera, 2013). In natural academic settings, both performanceapproach and performance-avoidance goals were indeed found to relate to marked interest for social comparison (Darnon, Dompnier, Gilliéron, \& Butera, 2010; see also Bounoua et al., 2012) and particular focus on social status differences (Levy, Kaplan, \& Patrick, 2004). In this regard, performance goals should particularly affect social interactions. That is, in addition to driving self-regulation strategies (Elliot \& Moller 2003), performance goals may also drive self-other regulation strategies. Next we discuss how.

\section{Performance Goals and Agency in Interpersonal Behaviors}

The interpersonal circumplex model has proven to be of substantial heuristic and integrative value for the conceptualization, categorization, or assessment of interpersonal behaviors (Wiggins, 2003). This model—notably used in educational settings (e.g., Ojanen, Grönroos, \& Salmivalli, 2005; Rodkin, Ryan, Jamison, \& Wilson, 2013)_proposes a taxonomy of interpersonal behaviors as defined by two orthogonal dimensions: (a) communal behaviors vary along an horizontal axis from friendliness to hostility and (b) agentic behaviors vary along a vertical axis from dominance to submission (Horowitz, 2004).

Importantly for the present research, Conroy and his colleagues (2009) have associated the interpersonal circumplex model with the achievement goal framework. As far as the horizontal dimension is concerned, they argued that performance goals are related to interpersonal behaviors having a low level of communion (i.e., cold/distant behaviors). However, concerning the vertical dimension, the authors remained cautious, saying that "performancebased goals seem [. . .] to lead to more-agentic variations in interpersonal behaviors" before adding that "it would be important to determine how [valence] of achievement goals influence social behavior" (pp. 395-396). Drawing on their theoretical proposal, we argue that performance-approach goals relate to highly agentic (i.e., dominant) interpersonal behaviors, whereas performanceavoidance goals relate to poorly agentic (i.e., submissive) interpersonal behaviors.

On the one hand, in line with this idea, performance-approach goals have been found to be associated with a certain number of dominant interpersonal behaviors in academic contexts, such as antisocial behaviors in the classroom (e.g., disrupting the class, annoying the teacher, breaking the classroom rules; Shim, Cho, \& Wang, 2013), middle and high school students' reduced interest in interethnic contact (Migacheva \& Tropp, 2013), and the emergence of an autocratic leadership style within small learning groups (Yamaguchi, 2001). As a matter of fact-given their symmetry in terms of valence-performance-approach goals were

\footnotetext{
${ }^{1}$ It is worth noting that, according to some authors, mastery goals can be divided into mastery-approach goals and mastery-avoidance goals (Elliot \& McGregor, 2001; Van Yperen, 2006); however, the current discussion will not bring this distinction into play, as it is not relevant for the present research.
} 
found to be positively associated with self-reported measures of the behavioral activation system, defined as a behavioral facilitator in responses to environmental stimuli (Bjørnebekk, 2007; Elliot \& Thrash 2002; see also Bjørnebekk \& Diseth, 2010).

On the other hand, performance-avoidance goals have been found to be associated with a certain number of submissive interpersonal behaviors, such as not participating in classrooms (Jansen, 2006), college freshmen's interaction anxiety (Valentiner, Mounts, Durik, \& Gier-Lonsway, 2011), or high school students' reduced intentions of instrumental help-seeking through an increase in its perceived social cost (i.e., fear of being perceived as stupid by a peer; Roussel, Elliot, \& Feltman, 2011). As a matter of fact-given, again, their symmetry in terms of valenceperformance-avoidance goals were found to be positively associated with self-reported measures of the behavioral inhibition system, defined as a behavioral inhibitor in responses to environmental stimuli (Bjørnebekk, 2007; Elliot \& Thrash 2002; see also Bjørnebekk \& Diseth, 2010). ${ }^{2}$

As mentioned in the opening paragraph, the fact that performance-approach and performance-avoidance seem to respectively predict social dominance and social submission might be due to the self-evaluation threat potentially elicited by an other's competence (Muller \& Butera, 2007). In educational settings, learners continuously engage in social comparison of competences and are spontaneously prone to compare upward (Blanton, Buunk, Gibbons, \& Kuyper, 1999; Huguet, Dumas, Monteil, \& Genestoux, 2001). For performance goal-oriented learners, the superior competence of a social comparison target may be perceived as a particular threat, and - if not reduced - upward social comparison becomes problematic for self-identity (Mugny, Butera, \& Falomir, 2001), self-esteem (Tesser, 1988), and self-competence (Quiamzade \& Mugny, 2001). Thus, there are reasons to believe that, in interactions with a more-competent other, performance goals will work as a tool that regulates interpersonal behavior: Performance-approach would trigger an appetitive self-other regulation system, and performance-avoidance goals an aversive selfother regulation system.

\section{Performance Goals as Regulators of Social Interaction With More-Competent Others}

How do performance-oriented learners behave when facing a high-achieving schoolmate, a more advanced pupil, or a higher ranked student? As mentioned earlier, performance goals tend to be associated with social status goals (Hicks, 1997) and perception of more-competent others as a threat to self-evaluation (Ryan \& Pintrich, 1997). For instance, in a peer-tutoring context, namely problem solving under the tutelage of an adult, Newman and Schwager (1995) showed that the endorsement of performance goals had a deleterious effect on interpersonal exchanges. More broadly, while working with more-competent others, elementary school students given performance goal instructions were unlikely to benefit from the interaction in terms of learning (Gabriele \& Montecinos, 2001) and displayed low accuracy in comprehension monitoring (i.e., detecting their own comprehension failures; Gabriele, 2007).

The aforementioned studies suggest that performance goals qualitatively impact social interactions with more-competent others. This phenomenon might be due to two concurrent mecha- nisms. First, performance goals-when associated with an approach orientation-may lead to a dominant form of social behavior regulation. For instance, it has been shown that performance-approach goal-oriented individuals engaged in more deceptive information exchanges (i.e., a highly agentic behavior) when a partner was presented as being of high (vs. low) competence (Poortvliet, Anseel, Janssen, Van Yperen, \& Van de Vliert, 2012; see also Poortvliet, 2013). Second, performance goalswhen associated with an avoidance orientation-may lead to a submissive form of social behavior regulation. For instance, it has been shown that performance-avoidance individuals engaged in more free-riding behaviors (i.e., a poorly agentic behavior, to the extent that the responsibility of the work is left to the partners) when a dyadic partner was perceived as being extremely (vs. mildly) competent (Schoor \& Bannert, 2011).

In sum, the literature reviewed above suggests that another's superior competence strengthens the agency of interpersonal behaviors when individuals pursue performance-approach goals and weakens it when individuals pursue performance-avoidance goals. In order to study these opposing processes, an ideal social behavior that disentangles dominant from submissive behaviors is sociocognitive conflict regulation. Socio-cognitive conflict regulation corresponds to the interpersonal behavior displayed by an individual to cope with a disagreeing other (Doise \& Mugny, 1984). As seen in the next section, socio-cognitive conflict regulation might lead to dominant responses (i.e., individuals staying on their own position and invalidating that of the other) or-conversely-to submissive responses (i.e., individuals espousing the other's position and invalidating their own).

\section{Conflict Regulation}

In the study of learning, educational psychologists have long discussed the crucial role of social interactions in the dynamic of competences acquisition (for a historical and theoretical review, see Johnson \& Johnson, 2009). They more notably stressed the importance of inter-individual disagreement (for a review, see Butera, Darnon, \& Mugny, 2010; Levine, Resnick, \& Higgins, 1993; see also Kruger, 1993). Given the usual complexity and plurality of teaching and learning materials, such disagreement-or socio-cognitive conflict-on a given task in which aptitudes are at stake is very frequent. The crucial role of sociocognitive conflict has been documented in various topical domains such as scientific knowledge building (e.g., creationism vs. theory of evolution: Foster, 2012; climate change skepticism vs. global warming: Nussbaum, Sinatra, \& Owens, 2012), mathematical problem solving (Prusak, Hershkowitz, \& Schwarz, 2012), and

\footnotetext{
${ }^{2}$ It should be mentioned that performance-avoidance goals have also been found to be positively associated-although to a lesser extent-with the behavioral activation system (Bjørnebekk, 2007; Elliot \& Thrash 2002). Indeed, in specific contexts, Elliot and Thrash (2002) argued that performance-avoidance goal-oriented individuals could "attempt to override a general avoidance tendency by approaching normative competence (i.e., approach to avoid)" (p. 807). In this article, because we focus on the regulation of interpersonal behaviors, and more notably on that of conflict, whose approach (competitive regulation; i.e., confirming one's point of view) and avoidance (protective; i.e., conforming to another's point of views) components tend to be mutually exclusive, this potential crossrelationship between performance-avoidance and behavioral activation will not be discussed any further.
} 
even the teaching of sport and physical activities (Lafont, 2012). From an applied point of view, several scholars showed that socio-cognitive conflict could be used in both peer-managed classroom discussions (Wu, Anderson, Nguyen-Jahiel, \& Miller, 2013) and computer-assisted dyadic interactions (Roseth, Saltarelli, \& Glass, 2011; Saltarelli \& Roseth, in press).

Socio-cognitive conflict is characterized by a double uncertainty: On the one hand it calls individuals' mastery of the task into question (the "cognitive" part of conflict: "Is my answer correct?"; Piaget, 1952, 1985), while, on the other hand, it raises doubts about self-competence relative to that of the other (the "social" part of conflict: "Is the other more competent than me?"; Doise \& Mugny, 1984). When the disagreeing other is perceived as an informational support, the "cognitive question" prevails. Hence, individuals tend to regulate conflict in an epistemic way, namely by considering the validity of each other's answers and working deeply through the problem. Conversely, when the disagreeing other is perceived as a threat for self-evaluation, the "social question" is more likely to prevail. Hence, individuals tend to regulate conflict in a relational way, namely by defending their competence (Darnon, Doll, \& Butera, 2007). Thus, in order to study our general hypothesis that performance goals can function as a key determinant of the specific interpersonal behavior displayed during disagreement with more-competent others, the present research uses relational conflict regulation as the target interpersonal behavior.

More precisely, when facing a threatening disagreeing partner, individuals have two possible ways to regulate conflict in a relational manner: (a) they can confirm their viewpoint, while invalidating that of the other-namely a highly agentic, dominant behavior; or (b) they can conform to the other's viewpoint and subordinate their own-namely a poorly agentic, submissive behavior. The former case, which corresponds to a self-confirmatory strategy (i.e., resisting others' influence; Butera \& Mugny, 2001; Psaltis \& Duveen, 2006), has been designated in recent research as competitive relational regulation (Sommet et al., 2014). In the study of dialogical argumentation within learning dyads, this corresponds to adversarial argumentation (disputational dialogue without openness to an alternative viewpoint; Asterhan, 2013). The latter case, which corresponds to a mere compliance strategy (i.e., submitting to the other's influence; Quiamzade, 2007), has been designated as protective relational regulation (Sommet et al., 2014). In the study of dialogical argumentation, this corresponds to quick consensus seeking (cumulative dialogue without any critical exploration; Asterhan, 2013).

\section{Conflict Regulation With More-Competent Others}

How do learners usually regulate conflict with a morecompetent contradictor? With most educational systems being organized in such a way that higher competent sources (e.g., tutors, parents, higher achievers) provide knowledge to lower competent targets (e.g., tutees, children, lower achievers), socio-cognitive theorists soon became interested in this question. Early findings showed that children facing disagreeing adults (Carugati, De Paolis, \& Mugny, 1980-1981), one of their parents (Mugny, \& Carugati, 1989), or more advanced peers (Mugny \& Doise, 1978) gave short-lived, superficially processed, copycat versions of their more-competent other's response. Subsequent findings confirmed that, in a competitive context, participants confronted with a con- flicting answer emanating from a more-competent (vs. equally competent) partner embraced more his/her way of reasoning (Quiamzade, Tomei, \& Butera, 2000; for a review see Quiamzade \& Mugny, 2001). The fact that individuals facing more-competent disagreeing others regulate conflict in a protective way may be seen as a submissive interpersonal response to disagreement.

However, this evidence appears to be inconsistent in the literature, and in fact imitation elicited by more-competent partners appears to vary as a function of context. For instance, boys experiencing socio-cognitive conflict with more-competent girls have consistently shown a general tendency toward selfconfirmation (for a review, see Duveen \& Psaltis, 2013). In a similar fashion, experienced, fourth-year students facing a threatening disagreeing epistemic authority (i.e., teacher-researcher) have tended to resist the message that he/she delivers (Quiamzade, Mugny, Dragulescu, \& Buchs, 2003). The fact that individuals facing more-competent disagreeing others sometimes regulate conflict in a competitive way shows that the occurrence of an interpersonal dominant response to disagreement is also possible.

\section{Performance Goals as Regulators of Conflict With More-Competent Others}

In sum, the extant literature on conflict regulation shows that in some situations individuals tend to comply with more competent others, whereas in others they rather tend to sustain their own position. So far, however, no theoretical account of these variations has been put forward. We contend that performance goals could function as a critical factor to produce these variations. Thus, by applying the idea developed above-that performance goals qualitatively impact social interactions with more competent others, so that performance-approach goals lead to a dominant form of interpersonal behavior regulation, and performance-avoidance goals lead to a submissive form of interpersonal behavior regulation-we hypothesized that in dealing with a more-competent other, (a) performance-approach goals should orient conflict regulation toward more agency (i.e., resistance/dominance), in other words, what Sommet et al. (2014) have termed competitive conflict regulation, and (b) performance-avoidance goals should orient conflict regulation toward less agency (i.e., obedience/submission), in other words, protective conflict regulation.

\section{Hypotheses and Overview}

In this article, we predict that, when individuals interact with more-competent disagreeing others, performance goals will serve the function of regulating interpersonal behaviors aimed at coping with such a disagreement. Specifically, four studies aim at testing two hypotheses: (1) performance-approach goals should more positively predict competitive conflict regulation (self-confirmation) when facing a more-competent partner than when facing an equally competent partner, and (2) performance-avoidance goals should more positively predict protective conflict regulation (compliance) when facing a more-competent partner than when facing an equally competent partner. Performance-goal orientation was assessed (Studies 1, 3, and 4) and manipulated (Study 2). Participants interacted with a fictitious disagreeing partner on the Internet (Studies 1 and 3), reacted to a bogus disagreeing opinion on a questionnaire (Study 2), or took part in face-to-face videotaped 
interaction with a disagreeing other (Study 4). In Studies 1 and 2, the partner was presented as having either similar or superior academic competence compared to that of the participant. In Study 3 , the partner was presented as having either similarly or better performed at a bogus competence test; moreover, a control condition with no competence feedback was added. In Study 4, participants interacted in dyads and took the same bogus competence test, and received either similar or asymmetrical scores. Finally, relational conflict regulation was a self-reported measure (Studies 1 and 3), a more objective model-preference measure (Study 2), or a behavioral measure (Study 4).

\section{Study 1}

\section{Method}

Participants. One hundred thirty-nine students (78 females and 61 males with a mean age of 21.4 years; $S D=3.55)$ in the Bachelor of Social and Human Sciences program at a Frenchspeaking medium-size Swiss university volunteered in Study 1.

Procedure. The study was conducted on the Internet. University students were invited by mail to participate in an Internet study on collaborative e-learning. Respondents thought they interacted with another student. This bogus partner was either presented as being a bachelor student (same-competence partner condition, $N=$ 78) or a $\mathrm{PhD}$ student (superior-competence partner condition, $N=$ $61)$. Then, participants were given a text that described either the "primacy effect" (i.e., when asked to memorize a list of words, people tend to better recall the first terms, $N=69$ ) or the "recency effect" (i.e., when asked to memorize a list of words, people tend to better recall the last terms, $N=70$ ). Following the reading of this text, participants answered a question about the effect trend (i.e., "Imagine yourself as learning a series of words. Immediately after this task, to what extent would you be able to recall the first/last words?") so as to ensure that they were committed to the assigned primacy versus recency effect. Participants subsequently received a disagreeing reply from a fictitious partner. Participants who had read the text on primacy effect received an answer related to the recency effect and vice versa. In an open-ended question, participants were invited to react to this answer.

\section{Measures.}

Performance goals. Prior to the "interaction," individual differences in goal orientation were assessed. Items were extracted from Elliot and McGregor's (2001) Achievement Goal Questionnaire, validated in French by Darnon and Butera (2005). On a scale ranging from 1 (not at all) to 7 (completely), participants answered three items concerning performance-approach goals (e.g., "It is important for me to do better than other participants"; $\alpha=.91$, $M=3.29, S D=1.57$ ) and three items concerning performanceavoidance goals (e.g., "I just want to avoid doing poorly in this experiment"; $\alpha=.69, M=2.97, S D=1.21$ ). Correlation between the two aggregated scores was $r=.40, p=.001 .^{3}$

Self-reported conflict regulation. After having reacted to the bogus partner's answer, respondents were invited to report on their mode of conflict regulation. The six items were the ones used by Sommet and colleagues (2014): On a scale ranging from 1 (not at all) to 7 (completely), three items required the participants to indicate to what extent they regulated conflict in a competitive way (e.g., "did you try to show the partner was wrong"; $M=3.74$,
$S D=1.58)$. Another three items required them to indicate to what extent they regulated conflict in a protective way (e.g., "did you comply with your partner's proposition"; $M=3.54$, $S D=1.26$ ).

\section{Results}

Factorial structure of the scales. In preliminary analyses, factor analyses were conducted on the six conflict regulation items via principal-components extraction with oblimin rotation. As can be seen in Table 1, these analyses revealed the expected two-factor structure. On the one hand, Factor 1 accounted for $48.5 \%$ of the variance and comprised the three competitive relational regulation items. On the other hand, Factor 2 accounted for $16.7 \%$ of the variance and comprised the three protective relational regulation items. Correlation between the two factors was $r=-.39, p<$ .001 . Due to the weak Cronbach's alpha associated with protective regulation, factor scores were used as dependent variables. ${ }^{4}$ The competitive regulation score could range from -1.82 to 2.24 , and the protective regulation score from -1.83 to 3.15 .

Overview of the linear regression analyses. Multiple linear regression analyses were conducted to examine the effects of both performance goals and partner's competence on the two selfreported relational conflict regulation factor scores. In preliminary analyses, gender, assigned text (primacy vs. recency), and age were included in the regression model. The only significant effect was an age effect on competitive regulation, $\beta=-.17, F(1$, $128)=4.20, p<.05$. Mean-centered age was therefore entered in further analyses. As our hypothesis amounts to an interaction effect, it is necessary to take into account the interactions between the covariate and the manipulated independent variable (Yzerbyt, Muller, \& Judd, 2004). Thus, our model contained nine predictors: mean-centered performance-approach goals, mean-centered performance-avoidance goals, partner's competence $(-.5$ for same competence and +.5 for higher competence), the three first-order interactions, the second-order interaction, plus the mean-centered age, and the interaction between mean-centered age and partner's competence.

Self-reported competitive regulation. A main effect of performance approach goals was found. The more participants endorsed performance-approach goals, the more they reported having regulated conflict in a competitive manner, $\beta=.29, F(1,129)=9.51$, $p<.003, \eta_{\mathrm{p}}^{2}=.07$. More interestingly, the predicted interaction

\footnotetext{
${ }^{3}$ It should be noted that (a) performance-approach goals items used in Studies 1, 3, and 4 emphasized more normative comparison (i.e., "normative goals") than competence demonstration (i.e., "appearance goals"); (b) items of performance-avoidance goals items used in the same studies did not include an explicit normative reference. However, as far as interpersonal context is concern, normative and appearance goals are suspected to predict similar effects (Senko, Hulleman, \& Harackiewicz, 2011), and implicit and explicitly normative performance-avoidance goals seem to lead to the same pattern of results (Elliot \& Murayama, 2008).

${ }^{4}$ Cronbach's alphas were $\alpha=.78$ for competitive regulation and $\alpha=$ .60 for self-reported protective regulation. Due to the low alpha of the latter construct, we decided to use factor scores as dependent variables. However, regression analyses on the aggregated scores led to the same pattern of results. Indeed, in Study 1 the predicted interaction between performance-approach goals and partner's competence on competitive regulation was significant, $\beta=.18, F(1,129)=3.93, p<.05, \eta_{\mathrm{p}}^{2}=.03$, as was the predicted interaction between performance-avoidance goals and partner's competence on protective regulation, $\beta=.30, F(1,129)=9.69$, $p<.003, \eta_{\mathrm{p}}^{2}=.07$.
} 
Table 1

Conflict Regulation Items and Their Factor Loading Using Principal-Components Extraction With Oblique Rotation (Oblimin)

\begin{tabular}{|c|c|c|c|c|}
\hline \multirow[b]{2}{*}{ Variable } & \multicolumn{2}{|c|}{ Study 1} & \multicolumn{2}{|c|}{ Study 3} \\
\hline & Factor 1 & Factor 2 & Factor 1 & Factor 2 \\
\hline \multicolumn{5}{|l|}{ Items } \\
\hline \multicolumn{5}{|l|}{$\begin{array}{l}\text { When reacting to your partner's answer, to what } \\
\text { extent did you ... }\end{array}$} \\
\hline try to show you were right? & .86 & -.27 & .83 & .01 \\
\hline resist and maintain your initial position? & .75 & -.31 & .69 & -.23 \\
\hline try to show he (she) was wrong? & .85 & -.30 & .81 & -.16 \\
\hline think his (her) answer was more correct than yours? & -.38 & .78 & -.20 & .75 \\
\hline try to comply with his (her) opinion? & -.27 & .84 & .06 & .79 \\
\hline agree with his (her) own way of viewing things? & -.68 & .54 & -.43 & .58 \\
\hline$\%$ of explained variance & 47.98 & 16.78 & 35.26 & 22.95 \\
\hline
\end{tabular}

Note. Factor loadings $>.45$ are in boldface.

between performance-approach goals and partner's competence was significant, $\beta=.19, F(1,129)=4.38, p<.04, \eta_{\mathrm{p}}^{2}=.03$. When the partner was presented as being more competent, the higher the performance-approach goals, the higher the competitive regulation, $\beta=.49, F(1,129)=12.42, p<.001, \eta_{\mathrm{p}}^{2}=.09$, whereas, when the partner was presented as being equally competent, such relationship was not observed, $\beta=.09, F<1$, ns (see Figure 1, left panel). Although not part of our hypothesis, it is worth noting that the interaction between performance-avoidance goals and partner's competence was also significant, $\beta=-.24$, $F(1,129)=6.90, p<.01, \eta_{\mathrm{p}}^{2}=.05$. Last, as reported above, age was negatively associated with competitive regulation, $\beta=-.17$, $F(1,129)=4.09, p<.05, \eta_{\mathrm{p}}^{2}=.03$. No other effect reached significance.

Self-reported protective regulation. As expected, the interaction between performance-avoidance goals and partner's competence was significant, $\beta=.25, F(1,129)=6.65, p<.02, \eta_{\mathrm{p}}^{2}=$ .05 . When the partner was presented as being more competent, the higher the performance-avoidance goals, the higher the protective regulation, $\beta=.38, F(1,129)=6.19, p<.02, \eta_{\mathrm{p}}^{2}=.05$, whereas, when partner was presented as being equally competent, such relationship was not observed, $\beta=-.12, F<1$, ns (see Figure 1, right panel). No other predictor included in the model yielded significant effects.

\section{Discussion}

In line with our first hypothesis, these results indicated that, when the partner was more competent, the more individuals pursued performance-approach goals, the more they regulated conflict in a competitive way, which is not the case when the partner was equally competent. Furthermore, in line with our second hypothesis, results indicate that, when the partner was more competent, the more individuals pursued performance-avoidance, the more they regulated conflict in a protective way, which was not the case when the partner was equally competent. Additionally, the analyses revealed that performance-approach goals were associated with less-protective regulation, when partner's competence was higher as opposed to equal. This phenomenon does not come as a surprise as, from a theoretical perspective, competitive and protective regulations are negatively related constructs (i.e., the higher the self- confirmation, the lower the compliance), and, from an empirical perspective, outcomes variables of the present study are negatively correlated. Thus, the present study supports the idea that individuals endorsing performance goal have two distinct manners to regulate interpersonal behaviors when dissenting with a morecompetent other: performance-approach goals lead to regulate conflict in a competitive way, whereas performance-avoidance goals lead to regulate conflict in a protective way.

However, in Study 1, goals were measured as dispositional variables, which prevented us from establishing causal links between performance goals and relational conflict regulation with a more-competent other. Study 2 addresses this issue by manipulating goals. Moreover, in Study 1, we used a direct and quite transparent measure of conflict regulation. Self-reported measures may facilitate participants to provide responses that they perceive as being more socially desirable or as matching the purpose of the research (Darnon, Dompnier, Delmas, Pulfrey, \& Butera, 2009; Razavi, 2001). Thus, one might argue that a less controllable outcome variable should be used to provide convergent validity to the present results.

Therefore, using a paper-and-pencil adaptation of our experimental paradigm, Study 2 tested the effect of manipulated performance goals and relative competence on the relative preference between two models: a "confirmation model" (corresponding to competitive regulation) and a "compliance model" (corresponding to protective regulation). Compared to an equally competent partner, we hypothesized that when exposed to the disagreeing answer of a more-competent partner, performance-approach goals would predict higher ratings of the "confirmation model" over the "compliance model" than would performance-avoidance goals.

\section{Study 2}

\section{Method}

Participants. Seventy-three French vocational school students (agricultural and technical industrial training) were invited to participate in the experiment while having a free period in a study room of their school. Three participants had uncommon studentized deleted residuals on the relevant measure and were therefore 
- Superior-competence partner condition

-- - Same-competence partner condition
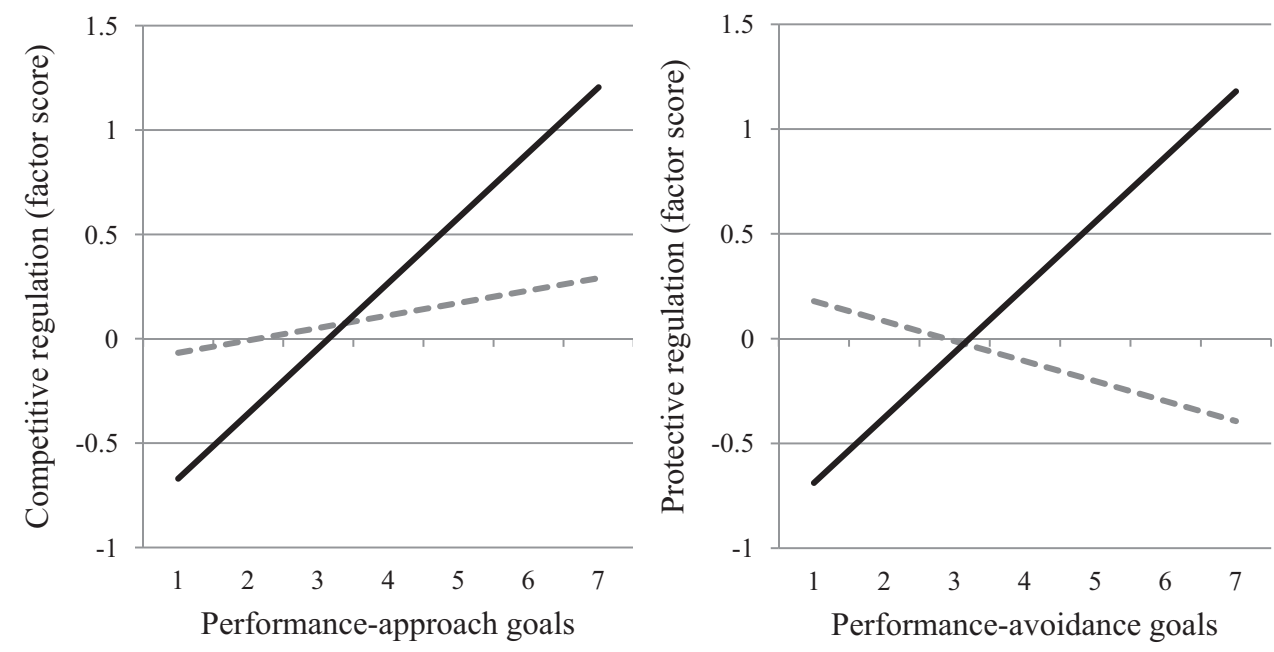

Figure 1. Competitive and protective regulation as a function of, respectively, performance-approach goals (on the left) and performance-avoidance goals (on the right) and partner's competence (Study 1).

dropped from the analysis. The cutoff point set by Kutner, Nachtsheim, Neter, and Li (2004), namely DFFITS $>2 \mathrm{~V}(\mathrm{p} / \mathrm{n})$, was used. The final sample consisted of 29 women and 40 men (1 was missing a gender response). Due to an oversight during questionnaire elaboration, participant age was not gathered; their school level corresponded to Grades 10-12, with an age typically ranging from 16 to18.

Procedure. Participants were told that the study consisted in solving a problem. In doing so, they would have access to the answer of another student at their school. Subsequently, respondents were given either performance-approach goal instructions (i.e., "[you should] try to perform better than the majority of students"; $N=36$ ) or performance-avoidance goal instructions (i.e., "[you should] try to avoid performing less well than the majority of students"; $N=34$ ). These instructions were the ones developed and validated by Darnon, Harackiewicz, Butera, Mugny, and Quiamzade (2007). After the goal induction, as in Study 1, participants read a text that described either the primacy effect $(N=35)$ or the recency effect $(N=35)$ and answered the same question about the effect trend. Then they read the opinion of an alleged partner student. The "partner" was presented as being either in the same grade level (same-competence partner condition; $N=38$ ) or in a higher one (superior-competence partner condition; $N=32$ ). His/her opinion followed the recency model for participants who had read the text on primacy and vice versa. Finally, participants were presented with two models following from the theory presented in the text. The graphs illustrated possible relationships between word position in the list and recall probability, namely a decreasing curve (corresponding to the primacy effect) and an increasing curve (corresponding to the recency effect).

\section{Measures.}

Model preference. Participants had to evaluate whether two models were correct, defendable, and convincing on the basis of three items rated on a scale ranging from 1 (not at all) to 7 (completely). The first model illustrated the respondent's answer ("the confirmation model"; $\alpha=.97, M=4.60, S D=2.15$ ), and the second the other student's answer ("the compliance model"; $\alpha=.95, M=3.53, S D=2.12$ ). The correlation between the two aggregated scores was $r=-.73, p<.001$. In the context of this study, as mentioned above, we wanted to depart from a selfreported measure and focus on the participants' preference for confirmation or compliance. Thus, as far as competitive regulation is concerned, namely validating one's own answer while invalidating that of the other, it was operationalized as the preference for the confirmation model over the compliance one. As far as protective regulation is concerned, namely validating the other's answer while invalidating that of the self, it was operationalized as the preference for the compliance model over the confirmation one.

Hence, a new variable was computed by subtracting the rating of the confirmation model from the rating of the compliance model $(M=1.06, S D=3.98)$. A value of zero indicated that neither one's own position nor the partner's position was preferred. A positive value indicated preference for the predictive model that referred to sticking to one's own position, theoretically corresponding to competitive regulation. A negative value indicated preference for the predictive model that referred to following the partner's point of view, theoretically corresponding to protective regulation.

\section{Results}

Multiple linear regression analyses were conducted with the goal variable (coded -.5 for performance-avoidance goals and .5 for performance-approach goals), the partner's competence (coded -.5 for same academic competence and .5 for higher academic competence), and the interaction on the model preference score. 
Preliminary analyses indicated that neither the assigned text (primacy vs. recency) nor the gender of the participant significantly predicted the outcome variable. Thus, these variables were not included in further analyses. As expected, the predicted interaction between goals and partner's competence was significant, $\beta=.28, F(1,66)=5.60, p<.03, \eta_{\mathrm{p}}^{2}=.08$., In comparison to performance-avoidance goals, performance-approach goals predicted more preference for the "confirmation model" over the "compliance model" (i.e., a more positive difference score) when the partner's competence was higher, $\beta=.39, F(1,66)=4.90$, $p<.03, \eta_{\mathrm{p}}^{2}=.07$, than when it was equal, $\beta=-.17, F(1,66)=$ $1.18, p=.28, \eta_{\mathrm{p}}^{2}=.02$ (see Figure 2 ). No other effect reached significance.

\section{Discussion}

Congruent with those of Study 1, the present results revealed an interaction between performance goals and the partner's academic competence on relational conflict regulation. When participants were confronted with a more-competent partner, performanceapproach goals predicted higher preference for a self-confirmatory model over the compliant model than did performance-avoidance goals. Such a difference was not observed when participants were confronted to an equally competent partner. Thus, in this study, where we manipulated goals and used preference for a confirmatory model over the compliant one as an outcome variable, the results correspond to a conceptual replication of Study 1, to the extent that preferential rating of the confirmatory model over the compliance model corresponds to the competitive relational regulation.

Nevertheless, one might argue that the partner's academic level is not a manipulation of relative competence per se. Indeed, it implies that participants infer from their partner's academic status the fact that $\mathrm{s} / \mathrm{he}$ is similarly versus more competent on the task. Thus, in Study 3, participants received an explicit competence feedback following a bogus test: Their fictitious partner was pre-

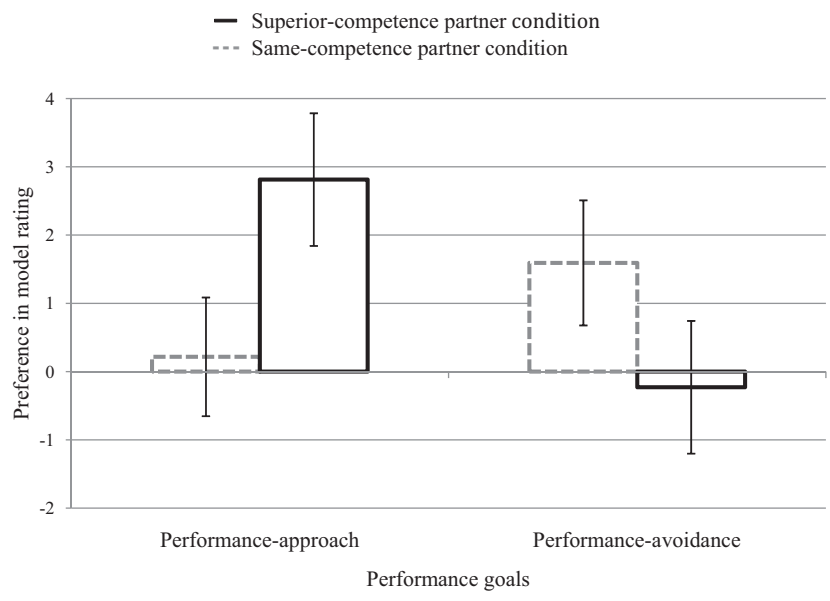

Figure 2. Preference for a model as a function of type of performance goals condition and partner's competence. A positive value refers to a preference for the "confirmation model," whereas a negative value refers to a preference for the "compliance model" (Study 2). Error bars represent standard error of the mean. sented as having a score that was either similar to theirs (equal relative competence) or higher (superior relative competence). Furthermore, to test an important corollary of the basic hypothesis, we added a control condition in which no score was given. Muller, Atzeni, and Butera (2004) reported that mere coaction, in the same way as upward comparison, elicits some threat to self-competence. Indeed, not knowing the competence level of a partner raises uncertainty about self-competence and generates a distractive focus on social comparison. Therefore, if it is true that in relational conflict people are concerned with competence, then individuals endorsing performance goals should regulate interpersonal behavior in a similar fashion regardless of whether the partner's competence is unknown or superior.

Using a slightly different experimental paradigm, in which participants' spontaneous position in the conflict was freely expressed (i.e., participants' intuitive beliefs in the phenomenon at hand) instead of being induced by a text (i.e., participants reading a text on the phenomenon at hand), as in the previous study, we hypothesized that (a) performance-approach goals would be more positively associated with competitive conflict regulation when the disagreeing partner has a higher or unspecified competence score than when the score is equal and (b) performance-avoidance goals would be more positively associated with protective conflict regulation when the disagreeing partner has a higher or unspecified competence score than when the score is equal.

\section{Study 3}

\section{Method}

Participants. Two hundred eighty students in the Social and Human Sciences program at a French-speaking medium-size Swiss university volunteered in Study 3. Two participants had uncommon studentized deleted residuals on the relevant measure and were therefore dropped from the analysis. Because of our large sample $(N>275)$, the cutoff point used in Study 2 was not conservative enough (Kutner et al., 2004). Thus, the cutoff point set by Freund and Littell (1991), namely rstudent $t_{\mathrm{i}}= \pm 2.5$ (Davis, 2006), was used. The final sample consisted of 289 bachelor $\left(N_{\mathrm{B}}=151\right)$, master $\left(N_{\mathrm{M}}=97\right)$, and $\mathrm{PhD}\left(N_{\mathrm{PhD}}=31\right)$ students ( $N_{\mathrm{O}}=6$ others; 4 missing data), 201 women and 88 men, with a mean age of 23.6 years $(S D=4.89)$.

Procedure. The study was conducted on the Internet. University students were invited by mail to participate in a study on social representations of bipolar disorder. As in Study 1, respondents thought they interacted with another student. First, they were invited to fill in a multiple-choice questionnaire supposedly assessing their and their partner's knowledge in psychopathology. Once they had completed the test, they received their competence score and that of the "partner": In the same-competence partner condition $(N=85)$, both scores were $65 / 100$; in the superiorcompetence partner condition $(N=111)$, the scores were $65 / 100$ for the participant and 80/100 for the partner; and in the control condition $(N=93)$, no feedback concerning their or their partner's competence was provided. Subsequently, participants were given a text describing bipolar disorder, which covered several issues but did not address the issue of its etiology. In a closed-ended question, participants were then asked "to give their opinion about the cause of the bipolar trouble." They had two possibilities: a nurture- 
based explanation ( $N=102$ participants opted for this option) or a nature-based explanation $(N=187$ participants opted for this option). After having justified their choice, they received a disagreeing reply from their "partner." Participants in support of a nature-based, biological explanation received an answer related to the nurture-based, environmental determinants of the disorder and vice versa. In an open-ended question, participants were invited to react to this answer.

\section{Measures.}

Performance goals. Prior to the "interaction," participants filled out the same goal questionnaire used in Study $1(\alpha=.90$, $M=3.09, S D=1.43$, for performance-approach goals; $\alpha=.79$, $M=2.87, S D=1.31$, for performance-avoidance goals). The correlation between the variables was $r=.52, p<.001$.

Self-reported conflict regulation. After having reacted to the bogus partner's answer, respondents were invited to report their mode of conflict regulation on a questionnaire including the same items as in Study $1(M=3.95, S D=1.24$, for competitive regulation; $M=3.52, S D=1.07$, for protective regulation).

\section{Results}

Factorial structure of the scales. In preliminary analyses, factor analyses were conducted on the six conflict regulation items via principal-components extraction with oblimin rotation. As can be seen in Table 1, factor analyses again revealed the two-factor structure, with Factor 1 accounting for $35.7 \%$ of the variance and comprising the three competitive relational regulation items and Factor 2 accounting for $22.8 \%$ of the variance and comprising the three protective relational regulation items. The correlation between the two factors was $r=-.19, p<.002$. As in Study 1 , due to the weak Cronbach's alpha associated with protective regulation, factor scores were used as dependent variables. ${ }^{5}$ The competitive regulation score could range from -2.56 to 2.31 , and the protective regulation score from -2.48 to 3.46 .

Overview of the linear regression analyses. Multiple linear regression analyses were conducted to examine the effects of performance goals and relative competence on self-reported relational regulation factor scores. Partner's competence was contrastcoded (Judd \& McClelland, 1989). In the contrast of interest, when partner's competence was equal, the variable was coded -2 ; when it was higher, it was coded +1 ; when it was non-specified, it was coded +1 . The orthogonal contrast was also computed, coding 0 for an equally competent partner, -1 for a more-competent partner, and +1 for the control condition. The model also included performance-approach and performance-avoidance goals, as well as their interactions with the contrasts. Preliminary analyses indicated that the outcome variables were not significantly predicted by the expressed opinion (nature vs. nurture), participant gender, academic level, or age. Thus, these variables were not included in further analyses. Our final model therefore contained 11 predictors: Contrast 1, Contrast 2, mean-centered performance-approach goals, mean-centered performance-avoidance goals, the five firstorder interactions, and the two second-order interactions.

Self-reported competitive regulation. As in Study 1, a main effect of performance-approach goals was found. The more participants endorsed performance-approach goals, the more they reported having regulated conflict in a competitive manner, $\beta=$ $.15, F(1,277)=4.70, p<.04, \eta_{\mathrm{p}}^{2}=.02$. More important, in line with our first hypothesis, the interaction between our contrast of interest and performance-approach goals was significant, $\beta=.14$, $F(1,277)=4.09, p<.05, \eta_{\mathrm{p}}^{2}=.014$, while the interaction with the orthogonal contrast was not, $F(1,277)=2.77, p=.10$. Performance-approach goals were found to be associated more positively with competitive regulation both when partner's competence was higher, $\beta=.11, F<1$, ns, and when it was non-specified, $\beta=.39, F(1,277)=10.81, p<.002, \eta_{\mathrm{p}}^{2}=.04$, than when it was equal, $\beta=-.05, F<1$, ns (see Figure 3, left panel). No other effect reached significance.

Self-reported protective regulation. A main effect of performance-avoidance goals was found. The more participants endorsed performance-avoidance goals, the more they reported having regulated conflict in a protective manner, $\beta=.15, F(1$, $277)=4.54, p<.04, \eta_{\mathrm{p}}^{2}=.02$. More important, in line with our second hypothesis, the interaction between our contrast of interest and performance-avoidance goals was significant, $\beta=.14, F(1$, $277)=4.36, p<.04, \eta_{\mathrm{p}}^{2}=.015$, while the interaction with the orthogonal contrast was not, $\beta=-.01, F<1$, ns. Performanceavoidance goals were found to be associated more positively with protective regulation both when partner's competence was higher, $\beta=.27, F(1,277)=4.93, p<.03, \eta_{\mathrm{p}}^{2}=.02$, and when it was non-specified, $\beta=.24, F(1,277)=3.86, p=.05$, $\eta_{\mathrm{p}}^{2}=.01$, than when it was equal, $\beta=-.06, F<1$, ns (see Figure 3 , right panel). Although not part of our hypothesis, it is interesting that the interaction between our contrast of interest and performanceapproach goals was also significant $\beta=-.15, F(1,277)=5.21$, $p<.03, \eta_{\mathrm{p}}^{2}=.02$, while the interaction with the orthogonal contrast was not, $\beta=-.03, F<1$, ns. Moreover, the interaction between the two performance goals was significant, $\beta=.15, F(1$, $277)=3.97, p<.04$. No other effect reached significance.

\section{Discussion}

Consistent with what was observed in Studies 1 and 2, but adding a control condition for partner's relative competence, the present results show that performance-approach goals and performance-avoidance goals are, respectively, more associated with competitive and protective regulation when the disagreeing partner is presented as having a superior or unspecified competence score than when presented as having identical competence.

Although the results of Studies 1, 2, and 3 were highly convergent, in these studies the disagreeing partner was always fictitious, and the interaction was therefore quite limited. In Study 4, we aim at replicating our findings in a more ecological context while testing the same hypotheses on behavioral measures. Dyads of participants came to the lab and obtained bogus competence scores. In the first condition, so as to recreate the "samecompetence partner condition" of the first three studies, the same

\footnotetext{
${ }^{5}$ Cronbach's alphas were $\alpha=.69$ for competitive regulation and $\alpha=$ .52 for self-reported protective regulation. As in Study 1, due to the low alpha of the latter construct we decided to use factor scores as dependent variables. However, regression analyses on the aggregated scores led to the same pattern of results. Indeed, the predicted interaction between performance-approach goals and partner's competence on competitive regulation was significant, $\beta=.15, F(1,277)=4.93, p<.03, \eta_{\mathrm{p}}^{2}=.02$, as was the predicted interaction between performance-avoidance goals and partner's competence on protective regulation, $\beta=.14, F(1,277)=4.53$, $p<.04, \eta_{\mathrm{p}}^{2}=.02$.
} 
- Superior-competence partner condition

.... Control condition (unspecified competences)

- - - Same-competence partner condition
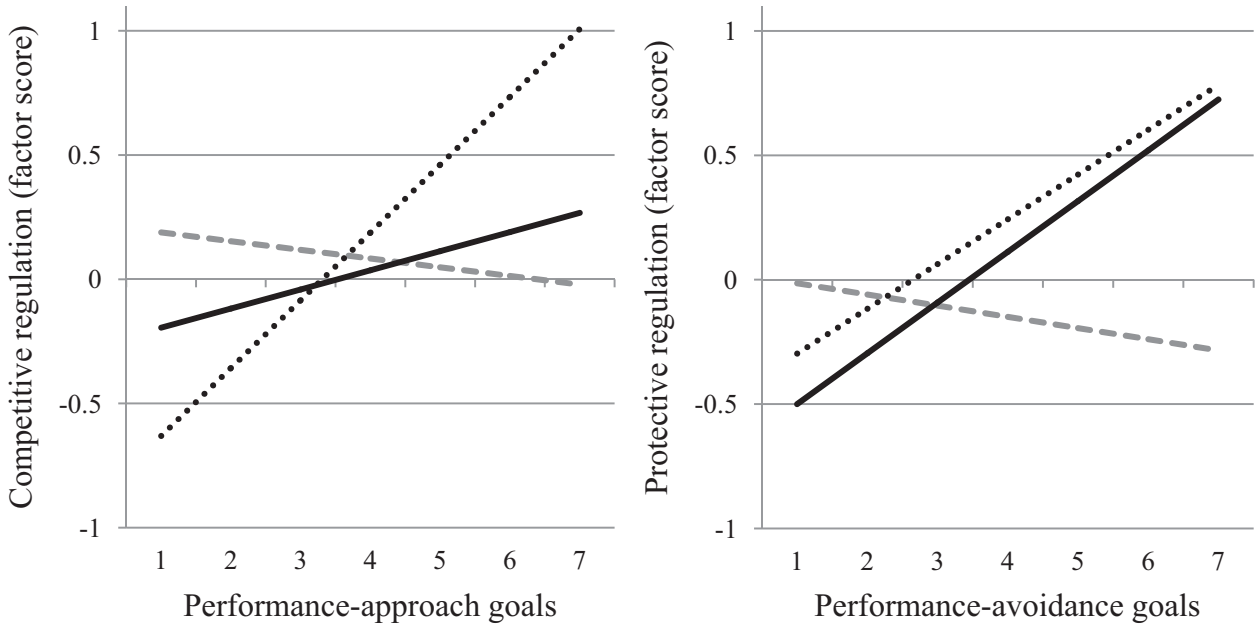

Figure 3. Competitive and protective regulation as a function of partner's competence (Study 3) and, respectively, performance-approach goals (on the left) and performance-avoidance goals (on the right).

score was given to both members of the dyad. In the second condition, so as to recreate the "superior-competence partner condition" of the first three studies, asymmetrical scores were given. This last scenario implies that one participant has a superior score and therefore - as a corollary — creates the supplementary case of one participant having an inferior score. A more competent partner should constitute a self-evaluation threat, whereas similarly or less-competent ones should not, and therefore result in a similar pattern of behavioral regulation. Participants were then invited to discuss a problem involving conflict. Independent judges were asked to count occurrences of competitive and protective regulation behaviors in the videotaped interactions. We hypothesized that (a) performance-approach would be associated with more competitive conflict regulation behaviors when the competence score obtained by the partner is higher than when it is equal or lower and (b) performance-avoidance would be associated with more protective conflict regulation behaviors when the competence score obtained by the partner is higher than when it is equal or lower.

\section{Study 4}

\section{Method}

Participants. Seventy-eight volunteers were recruited in the Human Sciences building of a medium-size French-speaking Swiss university. Outlier analysis revealed that one observation deviated from the others. Since nonlinear regressions were used in this study, contrary to the case for Studies 2 and 3, Cook's distance $(D>2)$ was used, as recommended by Xie and Wei (2007). The final sample consisted of 55 women and 22 men with a mean age of $21.9(S D=3.21)$.
Procedure. Same-sex dyads came to the lab to participate in a study on "social representations of mental illness." First, the experimenter invited them to fill in the same bogus questionnaire used in Study 3. The test was conducted on a laptop connected to the Internet, and at its completion, a competence score appeared on the screen. There were two possibilities: both participants of the dyad received a bogus feedback of 65/100 (same competence partner condition, $N=23$ ) or one participant of the dyad received a bogus feedback of 65/100 (superior-competence partner condition, $N=27$ ) while his/her partner received 80/100 (inferiorcompetence partner condition, $N=27$ ). Participants had to publicly announce their score to the experimenter, so that the partner would listen. Subsequently, the dyads were given two scientific texts describing the etiology of Alzheimer's disease. One participant of the dyads read arguments in favor of a biological explanation (i.e., gene coding for Apolipoprotein E), whereas the other one read arguments in favor of an environmental explanation (i.e., lack of social support). Finally, participants had to discuss the question, "What is the most probable cause of Alzheimer's disease?" The experimenter left the lab, and the interactions were videotaped.

Measures.

Achievement goals. Prior to the interaction and to the feedback, participants filled in the same goal questionnaire used in Studies 1 and $3(M=2.68, S D=1.39, \alpha=.85$, for performanceapproach; $M=3.00, S D=1.39, \alpha=.77$, for performanceavoidance). The correlation between the two variables was $r=.45$, $p<.001$.

Occurrences of relational conflict regulation behaviors. Two independent blind judges coded the interactions of the 39 video- 
taped discussions. The procedure was adapted from Asterhan and Schwarz (2009). Judges were asked to detect the occurrences of (a) denigration of the partner (i.e., unreasoned opposition with the position defended by the partner, labeled in Asterhan \& Schwarz, 2009, as "opposition," i.e., "overt verbal utterances of unreasoned disagreement," p. 383), (b) self-confirmation (i.e., unreasoned support of the position of the participant's text, labeled in Asterhan \& Schwarz, 2009, as "rebuttal," i.e., "response [aiming at] weakening [the other's] claim," p. 383); (c) compliance, i.e., unreasoned support of the position of partner's text (labeled in Asterhan and Schwarz (2009) as "agreement," i.e., "overt verbal utterances of unreasoned agreement" p. 383). It should be noted that, as our study is concerned with relational conflict regulation, which is theoretically non-related to focus on the task, only categories corresponding to unreasoned statements (described to the judges as being non-relevant: authoritative arguments, personal beliefs, etc.) in Asterhan and Schwarz were taken into account. The sum of the occurrences of denigration with the partner and selfconfirmation corresponded to behavioral competitive regulation $(M=0.62, S D=0.96)$. Occurrences of compliance corresponded to behavioral protective regulation $(M=0.38, S D=0.63)$. Initial inter-rater agreement was good $(\kappa=.76, p<.001$, for behavioral competitive regulation and $\kappa=.76, p<.001$, for behavioral protective regulation; Landis \& Koch, 1977). All disagreements were then resolved by direct interaction between the judges. The correlation between the two variables was $r=-.07, p=.56$.

\section{Results}

Violation of the assumptions of standard linear regression models. Because our dependent variables (i.e., behavioral competitive and behavioral protective regulation) are "count variables" (i.e., corresponding to a number of behavioral occurrences), observations are non-normally distributed. In such a case, linear regressions are no longer appropriate. Thus, we conducted a Poisson regression (King, 1988). Poisson regression assumes that (1) the outcome variable's variance equals its mean (one of Poisson distribution propriety is the fact that $\mathrm{E}(\mathrm{X})=\operatorname{var}(\mathrm{X})$ ) and (2) independence of errors (as the other types of regression, the error term of one observation $\left(\varepsilon_{\mathrm{i}}\right)$ is assumed to be independent of the error term of another observation $\left(\varepsilon_{\mathrm{i}}\right)$ ). First, to control for mild violation of the first assumption, we had to use robust standard errors for the parameter estimates (Cameron \& Trivedi, 2009). Second, as far as independence of errors is concerned, we calculated intraclass correlations. With such a distribution, Pearson's correlation coefficient has been shown to be the most reliable estimator (Tsagris, Elmatzoglou, \& Frangos, 2012). Neither behavioral competitive regulations $(r=-.03, p=.86)$ nor behavioral protective regulations $(r=-.24, p=.41)$ were found to be significantly correlated within dyads. Thus, analyses were conducted at the individual level (Kenny, Kashy, \& Cook, 2006).

Overview of the Poisson regression analyses. Multiple Poisson regression analyses were conducted on both behavioral relational conflict regulations. Partner's competence was contrastcoded. In the contrast of interest, when partner's competence was equal, the variable was coded -1 ; when it was lower, it was coded -1 ; when it was higher, it was coded +2 . The orthogonal contrast was also computed: Equal-competence partner was coded -1 , inferior-competence partner was coded 1 , and superior- competence partner was coded 0 . The two other independent variables were performance-approach and performance-avoidance goals. In preliminary analyses, the chosen theory (nature vs. nurture), gender and age were included in the regression model. The only significant effect was a gender effect (coded -.5 for women and +.5 for men) on protective regulation behaviors, $B=1.39$, Wald $\chi^{2}(1, N=77)=5.77, p<.02$. Gender was therefore entered in further analyses. As in Study 1, the interaction between the covariate and the manipulated independent variable was also taken into account (Yzerbyt et al., 2004). Thus, the Poisson regression analyses contained 14 predictors: the contrast of interest (participant's competence), the orthogonal contrast, mean-centered performance-approach goals, mean-centered performanceavoidance goals, the five first-order interactions, the two secondorder interactions, plus gender, the interaction between gender and our contrast of interest, and the interaction between gender and the orthogonal contrast.

In line with our first hypothesis, the analysis revealed a marginal interaction effect between our contrast of interest and performance-approach goals, $B=.18$, Wald $\chi^{2}(1, N=77)=3.65$, $p<.06$, while the interaction with the orthogonal contrast was not significant, Wald $\chi^{2}<1$, ns. Performance-approach goals were found to be more positively associated with occurrences of competitive behavior regulation when partner's competence was higher, $B=.31$, Wald $\chi^{2}(1, N=77)=1.85, p=.17$, than when it was either equal, $B=-.11$, Wald $\chi^{2}<1$, $n s$, or lower, $B=-.38$, Wald $\chi^{2}(1, N=77)=2.79, p=.10$ (see Figure 4, left panel). No other effect reached significance.

In line with our second hypothesis, the analysis revealed a significant effect of interaction between our contrast of interest and performance-avoidance goals, $B=.46$, Wald $\chi^{2}(1, N=77)=$ $12.72, p<.001$, while the interaction with the orthogonal contrast was not significant, Wald $\chi^{2}(1, N=77)=1.88, p=.17$. Performance-avoidance goals were found to be more positively associated with occurrences of protective regulation behavior when the partner's competence was higher, $B=1.10$, Wald $\chi^{2}(1$, $N=77)=18.04, p<.001$, than when it was either equal, $B=.12$, Wald $\chi^{2}<1$, ns, or lower, $B=-.66$, Wald $\chi^{2}(1, N=77)=1.67$, $p=.20$ (see Figure 4, right panel). As reported above, men (facing men) were found to regulate conflict in a more protective way than were women (facing women), $B=1.39$, Wald $\chi^{2}(1, N=77$ ) = $5.77, p<.02$. No other effects reached significance.

\section{Discussion}

Consistent with what was observed in Studies 1, 2, and 3, but in face-to-face interactions and using behavioral measures, the present results confirm the moderating role of relative competence on the link between performance goals and relational regulation. On the one hand, performance-approach goals tended to be more associated with competitive conflict regulation behaviors (i.e., unreasoned self-confirmation and disagreement) when the disagreeing partner was presented as being more competent than when presented as being equally or less competent. On the other hand, performance-avoidance goals were more associated with protective conflict regulation behaviors (i.e., unreasoned agreement) when the disagreeing partner was presented as being more competent than when presented as being equally or less competent. 
- Superior-competence partner condition

- - - Same-competence partner condition

..... Inferior-competence partner condition
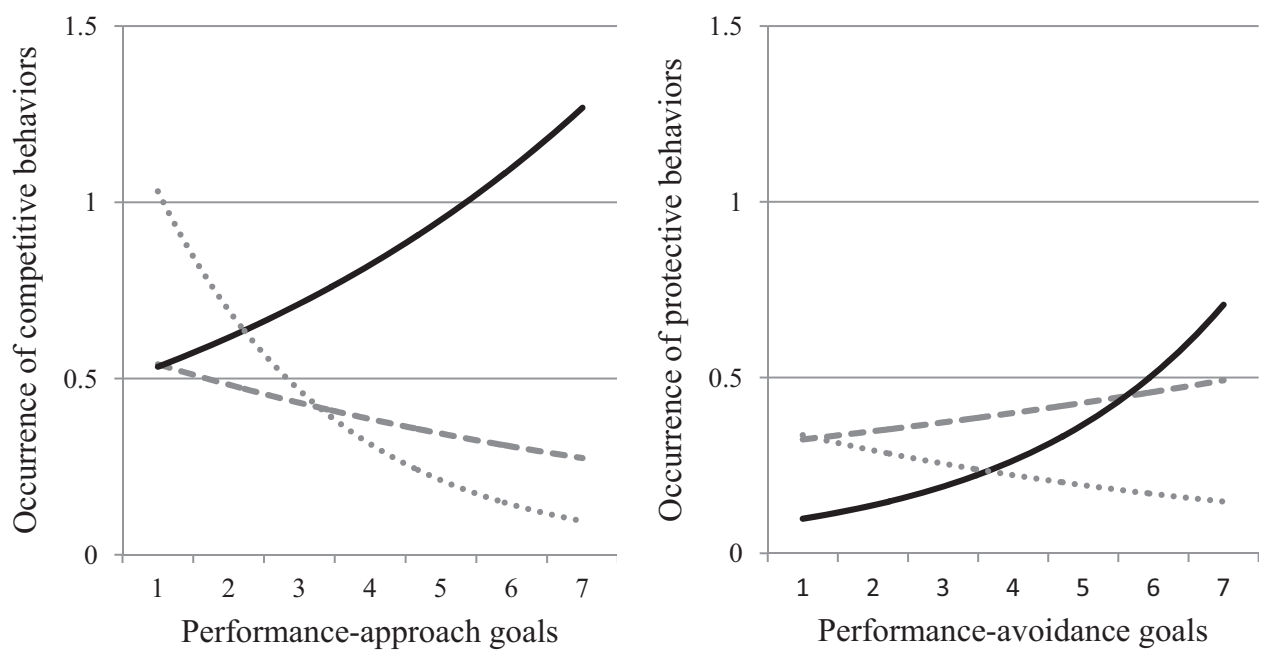

Figure 4. Occurrence of competitive and protective regulation behaviors as a function of partner's competence (Study 4) and, respectively, performance-approach goals (on the left) and performance-avoidance goals (on the right). Dependent variables of the Poisson regression equations (i.e., $\log \left(\mathrm{E}\left(Y_{i} \mid \mathrm{X}\right)\right)=\beta_{0}+\beta_{1} X_{\mathrm{i} 1}+\beta_{2} X_{\mathrm{i} 2}+$ $\left.\ldots+\beta_{p-1} X_{i, p}+\varepsilon_{i}\right)$ add to be transformed (i.e., $\left.\Leftrightarrow \mathrm{E}\left(Y_{i} \mid X\right)\right)=\exp \left(\beta_{0}+\beta_{1} X_{\mathrm{i} 1}+\beta_{2} X_{\mathrm{i} 2}+\ldots+\beta_{p-1}\right.$ $\left.X_{i, p}+\varepsilon_{i}\right)$, which explains the exponential shape of the curves.

Additionally, it should be noted that the analyses revealed an effect of gender: Women displayed less-protective behaviors (toward women) than men did (toward men). In this respect, it should be noted that the material of the task relates to the medical sciences, a field that is becoming increasingly feminized (Cheryan, 2012). It may well be that the women of our sample perceived the task as being slightly more adapted to their gender than did the men. Indeed, as far as feminine topics are concerned, women, as opposed to men, have been found to be less compliant, monopolizing the conversation, and paying less attention to the interlocutor (Dovidio, Brown, Heltman, Ellyson, \& Keating, 1988).

\section{General Discussion}

In dynamic learning systems (e.g., peer learning), disagreement with a more-competent other (e.g., a more-skilled student) is both a common and a hardly predictable situation. Indeed, in such circumstances, the self-evaluation threat elicited by the other's superior competence (Muller \& Butera, 2007) can induce either highly agentic, dominant, contending responses (e.g., Psaltis, 2011) or the opposite: poorly agentic, submissive, eluding responses (e.g., Quiamzade et al., 2000). Reconciling those divergent tendencies, the present research shows evidence of the performance goals function as a mechanism regulating the direction taken by interpersonal behaviors with more-competent other: Compared to a disagreeing partner presented as having a similar competence, when a disagreeing partner is presented as having a superior competence, performance-approach goals are associated with more competitive conflict regulation (i.e., self-confirmation) and performance-avoidance goals are associated with more protective conflict regulation (i.e., compliance).

The present set of studies was designed to provide complementary evidence of this phenomenon. First, regarding performance goals, Study 2 - through the manipulation of goals - was characterized by a high degree of internal validity, whereas Studies 1, 3, and 4-through the measurement of goals-were more ecological. Second, regarding the procedure, Study 4 -through the use of face-to-face videotaped interactions-was marked by a high degree of external validity, whereas Studies 1, 2, and 3-through the use of computer-assisted interactions with a fictional partnerallowed a tighter monitoring of the conflict situation. Third, regarding the materials, Studies 1 and 2 involved a disagreement on a cognitive psychology task (i.e., the serial position effect), whereas Studies 3 and 4 involved a disagreement on a medical science task (i.e., for Study 3, the etiology of bipolar trouble, where the participant's initial position was freely expressed; and, for Study 4, the etiology of Alzheimer's disease, where the participant's initial position was experimentally induced), attesting to the robustness of the effect throughout contexts. Fourth, regarding the outcome variable, socio-cognitive conflict regulation was assessed through a self-reported measure (Studies 1 and 3), a selfconfirmatory (vs. compliant) model preference (Study 3), and a behavioral measure (Study 4), indicating an overall convergent validity. Finally, regarding relative partner's competence, it was indirectly (i.e., academic status; Studies 1 and 2) and directly (i.e., bogus feedback; Studies 3 and 4) manipulated. 


\section{Theoretical and Practical Contributions}

The reported findings contribute in three important ways to research in educational psychology. The first contribution pertains to the link between achievement goals and interpersonal behaviors. Although peer interactions have long been regarded as a crucial factor in learning and teaching processes (Slavin, 1996; see also Bandura, 1971), and despite the need for more research on such a relationship having been emphasized in several recent articles (e.g., Darnon et al., 2012; Van Yperen \& Orehek, 2013), studies on the matter remain scarce. In the context of socio-cognitive conflict regulation, the present results provide convergent evidence that performance goals can work as a regulator of interpersonal behavior: As opposed to non-threatening others-here in the case of horizontal (Studies 1-4) or downward (Study 4) social comparison (Mendes, Blascovich, Major, \& Seery 2001)—when a partner is threatening for self-evaluation-here in the case of upward social comparison (Studies 1-4) or mere interaction (i.e., unspecified competence, Study 3; Muller et al., 2004)—performance-approach goals activate an appetitive self-other regulation system, leading to highly agentic behaviors, namely competitive regulation; in parallel, performance-avoidance goals activate an aversive selfother regulation system, leading to poorly agentic behaviors, namely protective regulation.

Scaling up the present results, we believe that the approach presented in the present article integrates interpersonal behaviors beyond the scope of socio-cognitive conflict regulation, or even group behaviors (Park \& Hinsz, 2006). Indeed, it could account for the fact that-due to the threatening nature of others' competenceperformance-approach goals have often been found to lead to highly agentic interpersonal behavior, be it in scholastic contexts (e.g., active cheating behaviors: Pulfrey \& Butera, 2013; negative attitudes toward helping others: Poortvliet \& Darnon, 2014) or in organizational ones (e.g., reduced ingroup team functioning: Dierdorff \& Ellington, 2012). It could also account for the fact that performance-avoidance goals have been often linked to poorly agentic interpersonal behaviors, be it - again-in academic settings (e.g., low level of extraversion: Zweig \& Webster, 2004; fear of negative peer judgment when seeking help: Tanaka, Murakami, Okuno, \& Yamauchi, 2001) or in organizational ones (e.g., withdrawing efforts from the work group or evading task responsibility: Chi \& Huang, 2014).

In sum, the moderating role of relative competence in the effects of performance goals on relational conflict regulation suggests promising avenues for future research linking performance goals to the full range of interpersonal behaviors (e.g., information sharing, leadership style, social loafing). Moreover, future research may consider the extent to which such relationships would hold in contexts where performance goals have a low degree of social utility (Dompnier, Darnon, \& Butera, 2013; for instance in a learning environment where selection is low or inexistent, such as amateur arts classes) or regulated by autonomous (vs. controlled) reasons (Vansteenkiste, Mouratidis, \& Lens, 2010; for instance in a learning environment where structured competition is low or inexistent, such as recreational sports).

The second contribution pertains to the link between relative competence and relational conflict regulation, and it solves the longstanding riddle of the direction of the interpersonal behaviors-more dominant versus more submissive-that follow the disagreement with a more-competent other. On the one hand, disagreements with more-competent others, compared to equal or more-incompetent others, have been found to elicit a more protective conflict regulation (i.e., mere imitation without any further elaboration; for a review, see Quiamzade \& Mugny, 2001). The present set of studies reveals that in fact such conflict regulation is predicted by performance-approach goals only. Yet, performanceavoidance goals endorsement has been shown to be higher for individuals seeing themselves as incompetent (e.g., subsequent to receiving poor exam grades; Senko \& Harackiewicz, 2005, Study 1; see also Pulfrey, Buchs, \& Butera, 2011), when one's own sense of competence is threatened (Brodish \& Devine, 2009), and for members of low socio-educational strata (Jury, Smeding, Court, \& Darnon, 2013). Hence, our results allow a comprehensive reinterpretation of the studies showing the effect of others' superior competence on protective regulation: Performance-avoidance goals may have played a key role in orienting individuals facing a more (vs. less or equally) competent partner toward submissive behaviors.

On the other hand, disagreements with more-competent others, compared to equal or more-incompetent ones, have been sometimes found to elicit more-competitive conflict regulation (i.e., self-confirmatory responses). The most striking example is represented by the literature on gender and socio-cognitive conflict regulation (Psaltis, 2011) showing, in mixed-sex dyads, "a general tendency of male [. . .] to resist being positioned as less knowledgeable" (p. 306). The present set of studies reveals that in fact such conflict regulation is predicted by performance-approach goals only. In this respect, in addition to unifying the discrepant findings on socio-cognitive regulation when disagreeing with more-competent others, our results allow a comprehensive rereading of Psaltis and colleagues' studies (Psaltis \& Duveen, 2006, 2007; Psaltis, Duveen, \& Perret-Clermont, 2009): Performanceapproach goals may have played a central role in orienting participants (in this case, boys) facing a more-competent partner (in this case, a girl) toward dominant behaviors.

The third contribution pertains to the effect of status in computer-mediated communication (CMC). Crowston and Kammerer (1998) argued that "the use of CMC promotes more equal exchanges by de-emphasizing social context cues or by permitting anonymity" (p. 6; for a critical review, see Spears \& Lea, 1994). Hence, through the "democratization" of the discursive practices, CMC could reduce the occurrences of both dominant (Hiltz \& Turoff, 1993) and inhibited (Kiesler, Siegel, \& McGuire, 1984) interpersonal behaviors. In contrast with such positions, Studies 1 and 3-in which participants communicated with a bogus partner through the Internet-showed that, in such a context, relative competence information could actually predict both competitive (for performance-approach goals oriented individuals facing a more-competent other) and protective (for performance-avoidance goals oriented individuals facing a more-competent other) conflict regulations. These findings echo the ones of Weisband, Schneider, and Connolly (1995), showing that the social influence dynamics as a function of relative status do not differ between computermediated and face-to-face communication. As massive open online courses (MOOCs) become increasingly used in education and the issue of distance interaction between students of such courses arises (Clarà \& Barberà, 2013), our results caution that relative competence could produce the same undesirable effects in a de- 
materialized as in a materialized learning environment. This element is to be borne in mind for optimizing the pedagogy of distance learning systems.

\section{Limitations}

Some limitations should be mentioned. First of all, one of Study 3's simple slopes for the analysis on competitive regulation fell short of significance, and one of Study 4's predicted interactions was marginally significant. That being said, it should be noted that, with our effects sizes being small to medium (i.e., $\eta_{\mathrm{p}}^{2} \in[.01$, .08], Richardson, 2011), recent development in statistical analysis has suggested that it is impossible for attempts at replication to be always successful (Francis, 2012). In the present case, the fact that the effects of all four studies appear-when taken as a whole- to be consistent, speaks to the coherence of our hypotheses.

Second, although the factorial structure of our self-reported conflict regulation scale revealed the two predicted factors, the score of protective regulation had a low Cronbach's alpha. The results obtained with these scales, however, were in line with those observed with model preference and behavioral measures; future research may combine these measures with other selfreported measures of interpersonal conflict-handling behaviors used in organizational psychology (Thomas \& Kilmann, 1978) or the self-reported resistance and compliance assessments developed in the literature on social power (Nesler, Aguinis, Quigley, Lee, \& Tedeschi, 1999).

Third, and finally, the ecological validity of experimental, labbased research is usually low, and our paradigms make no exception. In particular, (a) participants' competence levels were manipulated (instead of appraised), and (b) participants communicated with an unidentified (bogus) partner (instead of a known classmate). Thus, exploring the effect of learners' performance goals as moderated by their actual competence (e.g., inferred from their GPA) in a natural academic setting (e.g., during collaborative dialogues in classroom) would be a worthwhile follow-up study. Such a study would probably yield the same results as in the present experiments, although with enhanced effects due to the higher involvement of participants in the interaction. It should be noted, however, that in actual social and learning groups, each individual's academic competence is inextricably linked to a plurality of other variables (e.g., physical attractiveness, classroom climate, classroom mean academic level) combining to define his/her social status; furthermore, this social status evolves in a complex manner as individuals get to know each other (Anderson, John, Keltner, \& Kring, 2001). Hence, manipulating relative competence, using a bogus partner (Studies 1 to 3 ) and selecting students who were unacquainted with one another (Study 4) enabled us to reduce the impact of confounding variables. More generally, one might also argue that our participants were not in real, meaningful interaction situations, which might have resulted in unrealistic responses. Again, a study with freely interacting students, drawn from classes with known reputations in term of competence, would enhance the commitment of participants to their responses. It should be noted, however, that such a study should not reveal fundamentally different effects compared with the present experiments; indeed, a vast literature on social comparison processes has long shown that even the most purified experimental comparisons have very real consequences for participants, in terms of self-esteem, self-worth, perceived threat, perception of the comparison target, and behavior (e.g., Muller \& Butera, 2007; Quiamzade \& Mugny, 2009; Tesser, 1988).

\section{Practical Implications for Education}

Despite these limitations, the reported findings are the first to allow for predicting the interpersonal behaviors that result from the disagreement with a more-competent other: Performance-approach goals predict more competitive conflict regulation (i.e., selfconfirmation), and performance-avoidance goals more protective conflict regulation (i.e., compliance). In addition to the two theoretical contributions discussed above, these findings also suggest an important practical implication. First keep in mind that the ubiquity of competition at school-be it based on normative aspects (e.g., in school: grading practice; Pulfrey et al., 2011) or institutional aspects (e.g., at a university: selection process; Darnon et al., 2009)—contributes to the endorsement of both performance-approach and performance-avoidance goals (for a review, see Murayama \& Elliot, 2012) and, in fine, to the displaying of maladaptive interpersonal behaviors (for a review, see Poortvliet \& Darnon, 2010). However, the present results suggest that, even when pursuing performance-approach and performanceavoidance goals, in a context of equalized perceived competences, the adoption of dominant and submissive regulations may be lowered. This is an important point to the extent that it provides an insight into the mechanism involved in several methods that have been developed to weaken the undesirable effects of competence asymmetry within groups or dyads (for a review of such methods, see Cohen \& Lotan, 1995). For example, Aronson's (1978) “jigsaw classroom" is a technique that creates positive resource interdependence by distributing unique information to each group member, and therefore making the competence of each group member salient, which in turn requires one to reflexively coordinate the distributed information to allow the group to reach its goal or goals (see also Darnon, Buchs, \& Desbar, 2012). Another example is Tammivaara's (1982) "multiple ability treatment," where a supervisor stresses the fact that, when collectively carrying out a task, no one has all the necessary competences, but each one has some of the necessary competences. A final example, discussed more recently, is "reciprocal peer tutoring" (Ensergueix \& Lafont, 2010), where same-age peers of equal competences work on a task while alternatively taking the role of tutee (instructed to ask the other) or of tutor (instructed to explain to the other). For an exhaustive description of status interventions that could be used by educators, please refer to Webb (2009).

In conclusion, the present research reveals a hitherto unstudied function of performance goals in the regulation of self-other behaviors: When a disagreeing other is perceived as threatening for self-evaluation, here in the case of upward social comparison, performance-approach goals trigger highly agentic behaviors, selfconfirmatory strategies, and competitive regulation, whereas performance-avoidance goals trigger poorly agentic behaviors, compliance strategies, and competitive regulation. Such findings point to the need for instructors, from schoolteachers to tutors and trainers, to reduce competence asymmetry within the groups they are in charge of, so as to prevent the detrimental effects of conflict. 


\section{References}

Anderson, C., John, O. P., Keltner, D., \& Kring, A. M. (2001). Who attains social status? Effects of personality and physical attractiveness in social groups. Journal of Personality and Social Psychology, 81, 116-132. doi:10.1037/0022-3514.81.1.116

Aronson, E. (1978). The jigsaw classroom. Beverly Hills, CA: Sage.

Asterhan, C. S. C. (2013). Epistemic and interpersonal dimensions of peer argumentation: Conceptualization and quantitative assessment. In M. Baker, J. Andriessen \& S. Jarvela (Eds.), Affective learning together (pp. 251-272). New York, NY: Routledge.

Asterhan, C. S. C., \& Schwarz, B. B. (2009). Argumentation and explanation in conceptual change: Indications from protocol analyses of peer-to-peer dialog. Cognitive Science, 33, 374-400. doi:10.1111/j.1551-6709.2009 .01017.x

Bandura, A. (1971). Social learning theory. New York, NY: General Learning Press.

Barron, B. (2003). When smart groups fail. Journal of the Learning Sciences, 12, 307-359. doi:10.1207/S15327809JLS1203_1

Bjørnebekk, G. (2007). Reinforcement sensitivity theory and major motivational and self-regulatory processes in children. Personality and Individual Differences, 43, 1980-1990. doi:10.1016/j.paid.2007.06.010

Bjørnebekk, G., \& Diseth, Å. (2010). Approach and avoidance temperaments and achievement goals among children. Personality and Individual Differences, 49, 938-943. doi:10.1016/j.paid.2010.07.034

Blanton, H., Buunk, B. P., Gibbons, F. X., \& Kuyper, H. (1999). When better-than-others compare upward: Choice of comparison and comparative evaluation as independent predictors of academic performance. Journal of Personality and Social Psychology, 76, 420-430. doi: 10.1037/0022-3514.76.3.420

Boissicat, N., Pansu, P., Bouffard, T., \& Cottin, F. (2012). Relation between perceived scholastic competence and social comparison mechanisms among elementary school children. Social Psychology of Education, 15, 603-614. doi:10.1007/s11218-012-9189-Z

Bounoua, L., Cury, F., Regner, I., Huguet, P., Barron, K. E., \& Elliot, A. J. (2012). Motivated use of information about others: Linking the $2 \times 2$ achievement goal model to social comparison propensities and processes. British Journal of Social Psychology, 51, 626-641. doi:10.1111/ j.2044-8309.2011.02027.x

Brodish, A. B., \& Devine, P. G. (2009). The role of performanceavoidance goals and worry in mediating the relationship between stereotype threat and performance. Journal of Experimental Social Psychology, 45, 180-185. doi:10.1016/j.jesp.2008.08.005

Buchs, C., Gilles, I., Dutrévis, M., \& Butera, F. (2011). Pressure to cooperate: Is positive reward interdependence really needed in cooperative learning? British Journal of Educational Psychology, 81, 135-146.

Butera, F., Darnon, C., \& Mugny, G. (2010). Learning from conflict. In J. Jetten \& M. Hornsey (Eds.), Rebels in groups: Dissent, deviance, difference and defiance (pp. 36-53). New York, NY: Oxford University Press.

Butera, F., \& Mugny, G. (2001). Conflicts and social influences in hypothesis testing. In C. De Dreu \& N. De Vries (Eds.), Group consensus and minority influence: Implications for innovation (pp. 160-182). Oxford, United Kingdom: Blackwell.

Cameron, A. C., \& Trivedi, P. K. (2009). Microeconometrics using stata (Vol. 5). College Station, TX: Stata Press.

Carugati, F., De Paolis, P., \& Mugny, G. (1980-1981). Conflit de centrations et progrès cognitif, III: Régulations cognitives et relationnelles du conflit socio-cognitif [Conflict of centrations and cognitive progress, III: Cognitive and relational socio-cognitive conflict regulations]. Bulletin de Psychologie, 34, 843-851.

Cheryan, S. (2012). Understanding the paradox in math-related fields: Why do some gender gaps remain while others do not? Sex Roles, 66, 184-190. doi:10.1007/s11199-011-0060-Z
Chi, N. W., \& Huang, J. C. (2014). Mechanisms linking transformational leadership and team performance: The mediating roles of team goal orientation and group affective tone. Group \& Organization Management, 39, 300-325. doi:10.1177/1059601114522321

Clarà, M., \& Barberà, E. (2013). Learning online: Massive open online courses (MOOCs), connectivism, and cultural psychology. Distance Education, 34, 129-136. doi:10.1080/01587919.2013.770428

Cohen, E. G., \& Lotan, R. A. (1995). Producing equal-status interaction in the heterogeneous classroom. American Educational Research Journal, 32, 99-120. doi:10.3102/00028312032001099

Conroy, D. E., Elliot, A. J., \& Thrash, T. M. (2009). Achievement motivation. In M. R. Leary \& R. H. Hoyle (Eds.), Handbook of individual differences in social behavior (pp. 382-399). New York, NY: Guilford Press.

Crowston, K., \& Kammerer, E. (1998). Communicative style and gender differences in computer-mediated communication. In E. Bosah (Ed.), $\mathrm{Cy}$ berghetto or cybertopia? Race, class, and gender on the Internet (pp. 185-203). Retrieved from http://www.academia.edu/921309/Communicative style_and_gender_differences_in_computer-mediated_communications

Darnon, C., Buchs, C., \& Desbar, D. (2012). The jigsaw technique and self-efficacy of vocational training students: A practice report. European Journal of Psychology of Education, 27, 439-449. doi:10.1007/s10212011-0091-4

Darnon, C., \& Butera, F. (2005). Buts d'accomplissement, stratégies d'étude, et motivation intrinsèque: Présentation d'un domaine de recherche et validation française de l'échelle d'Elliot et McGregor (2001) [Achievement goals, study strategies, and intrinsic motivation: Presenting a domain of research and the French validation of Elliot \& McGregor's scale (2001)]. L'année psychologique, 105, 105-131. doi: $10.3406 /$ psy.2005.3821

Darnon, C., Doll, S., \& Butera, F. (2007). Dealing with a disagreeing partner: Relational and epistemic conflict elaboration. European Journal of Psychology of Education, 22, 227-242. doi:10.1007/BF03173423

Darnon, C., Dompnier, B., Delmas, F., Pulfrey, C., \& Butera, F. (2009). Achievement goal promotion at university: Social desirability and social utility of mastery and performance goals. Journal of Personality and Social Psychology, 96, 119-134. doi:10.1037/a0012824

Darnon, C., Dompnier, B., Gilliéron, O., \& Butera, F. (2010). The interplay of mastery and performance goals in social comparison: A multiple-goa perspective. Journal of Educational Psychology, 102, 212-222. doi: 10.1037/a0018161

Darnon, C., Dompnier, B., \& Poortvliet, M. P. (2012). Achievement goals in educational contexts: A social psychology perspective. Social and Personality Psychology Compass, 6, 760-771. doi:10.1111/j.1751-9004 2012.00457.x

Darnon, C., Harackiewicz, J., Butera, F., Mugny, G., \& Quiamzade, A. (2007). Performance-approach and performance-avoidance goals: When uncertainty makes a difference. Personality and Social Psychology Bulletin, 33, 813-827. doi:10.1177/0146167207301022

Davis, J. B. (2006). Statistics using SAS enterprise guide. Cary, NC: SAS Press.

Dierdorff, E. C., \& Ellington, J. K. (2012). Members matter in team training: Multilevel and longitudinal relationships between goal orientation, self-regulation, and team outcomes. Personnel Psychology, 65, 661-703. doi:10.1111/j.1744-6570.2012.01255.x

Dinger, F. C., Dickhäuser, O., Spinath, B., \& Steinmayr, R. (2013). Antecedents and consequences of students' achievement goals: A mediation analysis. Learning and Individual Differences, 28, 90-101. doi: 10.1016/j.lindif.2013.09.005

Doise, W., \& Mugny, G. (1984). The social development of the intellect. Oxford, United Kingdom: Pergamon Press.

Dompnier, B., Darnon, C., \& Butera, F. (2013). When performanceapproach goals predict academic achievement and when they do not: A 
social value approach. British Journal of Social Psychology, 52, 587596. doi:10.1111/bjso.12025

Dovidio, J. F., Brown, C. E., Heltman, K., Ellyson, S. L., \& Keating, C. F. (1988). Power displays between women and men in discussions of gender-linked tasks: A multichannel study. Journal of Personality and Social Psychology, 55, 580-587. doi:10.1037/0022-3514.55.4.580

Duveen, G., \& Psaltis, C. (2013). The constructive role of asymmetry in social interaction. In S. Moscovici, S. Jovchelovitch, \& B. Wagoner (Eds.), Development as a social process: Contributions of Gerard Duveen (pp. 133-154). London, United Kingdom: Routledge.

Dweck, C. S. (1975). The role of expectations and attributions in the alleviation of learned helplessness. Journal of Personality and Social Psychology, 31, 674-685. doi:10.1037/h0077149

Elliot, A. J. (1999). Approach and avoidance motivation and achievement goals. Educational Psychologist, 34, 169-189. doi:10.1207/ s15326985ep3403_3

Elliot, A. J. (2005). A conceptual history of the achievement goal construct. In A. J. Elliot \& C. Dweck (Eds.), Handbook of competence and motivation (pp. 52-72). New York, NY: Guilford Press.

Elliot, A. J., \& Harackiewicz, J. M. (1996). Approach and avoidance achievement goals and intrinsic motivation: A mediational analysis. Journal of Personality and Social Psychology, 70, 461-475. doi: 10.1037/0022-3514.70.3.461

Elliot, A. J., \& McGregor, H. A. (2001). A $2 \times 2$ achievement goal framework. Journal of Personality and Social Psychology, 80, 501-519. doi:10.1037/0022-3514.80.3.501

Elliot, A. J., \& Moller, A. C. (2003). Performance-approach goals: Good or bad forms of regulation? International Journal of Educational Research, 39, 339-356. doi:10.1016/j.ijer.2004.06.003

Elliot, A. J., \& Murayama, K. (2008). On the measurement of achievement goals: Critique, illustration, and application. Journal of Educational Psychology, 100, 613-628. doi:10.1037/0022-0663.100.3.613

Elliot, A. J., \& Thrash, T. M. (2002). Approach-avoidance motivation in personality: Approach and avoidance temperaments and goals. Journal of Personality and Social Psychology, 82, 804-818. doi:10.1037/00223514.82.5.804

Ensergueix, P. J., \& Lafont, L. (2010). Reciprocal peer tutoring in a physical education setting: Influence of peer tutor training and gender on motor performance and self-efficacy outcomes. European Journal of Psychology of Education, 25, 222-242. doi:10.1007/s10212-009-0010-0

Fawcett, L. M., \& Garton, A. F. (2005). The effect of peer collaboration on children's problem-solving ability. British Journal of Educational Psychology, 75, 157-169. doi:10.1348/000709904X23411

Foster, C. (2012). Creationism as a misconception: Socio-cognitive conflict in the teaching of evolution. International Journal of Science Education, 34, 2171-2180. doi:10.1080/09500693.2012.692102

Francis, G. (2012). The psychology of replication and replication in psychology. Perspectives on Psychological Science, 7, 585-594. doi: $10.1177 / 1745691612459520$

Fraser, B. J., \& Fisher, D. L. (1982). Predicting students' outcomes from their perceptions of classroom psychosocial environment. American Educational Research Journal, 19, 498-518. doi:10.3102/ 00028312019004498

Freund, R. J., \& Littell, R. C. (1991). SAS system for regression (2nd ed.). Cary, NC: SAS Institute.

Gabriele, A. J. (2007). The influence of achievement goals on the constructive activity of low achievers during collaborative problem solving. British Journal of Educational Psychology, 77, 121-141. doi:10.1348/ 000709905X89490

Gabriele, A. J., \& Montecinos, C. (2001). Collaborating with a skilled peer: The influence of achievement goals and perception of partners' competence on the participation and learning of low-achieving students. Journal of Experimental Education, 69, 152-178. doi:10.1080/ 00220970109600654
Hicks, L. H. (1997). How do academic motivation and peer relationships mix in an adolescent's world? Middle School Journal, 28, 18-22.

Hiltz, S. R., \& Turoff, M. (1993). The network nation. Cambridge, MA: MIT Press.

Horowitz, L. M. (2004). Interpersonal foundations of psychopathology. Washington, DC: American Psychological Association. doi:10.1037/ 10727-000

Huguet, P., Dumas, F., Monteil, J. M., \& Genestoux, N. (2001). Social comparison choices in the classroom: Further evidence for students upward comparison tendency and its beneficial impact on performance. European Journal of Social Psychology, 31, 557-578. doi:10.1002/ ejsp. 81

Husén, T. (1994). Research paradigms in education. In T. Husén \& T. N. Postlethwaite (Eds.), The international encyclopaedia of education (2nd ed., Vol. 9, pp. 5051-5056). Oxford, United Kingdom: Pergamon Press.

Jansen, A. (2006). Seventh graders' motivations for participating in two discussion-oriented mathematics classrooms. Elementary School Jour nal, 106, 409-428. doi:10.1086/505438

Johnson, D. W., \& Johnson, R. T. (2009). An educational psychology success story: Social interdependence theory and cooperative learning. Educational Researcher, 38, 365-379. doi:10.3102/0013189X09339057

Judd, C. M., \& McClelland, G. H. (1989). Data analysis: A model comparison approach. San Diego, CA: Harcourt Brace Jovanovich.

Jury, M., Smeding, A., Court, M., \& Darnon, C. (2013, January 17-19). Performance-avoidance goals endorsement: Interaction between previous performance and socio-economic status. Poster presented at the 14th annual meeting of the Society for Personal and Social Psychology, New Orleans, LA.

Kaplan, A. (2004). Achievement goals and intergroup relations. In P. R. Pintrich \& M. L. Maehr (Eds.), Advances in research on motivation and achievement: Vol. 13. Motivating students, improving schools: The legacy of Carol Midgley (pp. 97-136). Amsterdam, the Netherlands: Elsevier.

Kenny, D. A., Kashy, D. A., \& Cook, W. L. (2006). Dyadic data analysis. New York, NY: Guilford Press.

Kiesler, S., Siegel, J., \& McGuire, T. W. (1984). Social psychological aspects of computer-mediated communication. American Psychologist, 39, 1123-1134. doi:10.1037/0003-066X.39.10.1123

King, G. (1988). Statistical models for political science event counts: Bias in conventional procedures and evidence for the exponential Poisson regression model. American Journal of Political Science, 32, 838-863. doi: $10.2307 / 2111248$

Kruger, A. C. (1993). Peer collaboration: Conflict, cooperation, or both? Social Development, 2, 165-182. doi:10.1111/j.1467-9507.1993 .tb00012.x

Kutner, M. H., Nachtsheim, C. J., Neter, J., \& Li, W. (2004). Applied linear statistical models. New York, NY: McGraw-Hill.

Lafont, L. (2012). Cooperative learning and tutoring in sports and physical activities. In B. Dyson \& A. Casey (Eds.), Cooperative learning in physical education: A research based approach (pp. 136-149). London, United Kingdom: Routledge.

Landis, J. R., \& Koch, G. G. (1977). An application of hierarchical kappa-type statistics in the assessment of majority agreement among multiple observers. Biometrics, 33, 363-374. doi:10.2307/2529786

Levine, J. M., Resnick, L. B., \& Higgins, E. T. (1993). Social foundations of cognition. Annual Review of Psychology, 44, 585-612. doi:10.1146/ annurev.ps.44.020193.003101

Levy, I., Kaplan, A., \& Patrick, H. (2004). Early adolescents' achievement goals, social status, and attitudes towards cooperation with peers. Social Psychology of Education, 7, 127-159. doi:10.1023/B:SPOE .0000018547.08294.b6

Liem, A. D., Lau, S., \& Nie, Y. (2008). The role of self-efficacy, task value, and achievement goals in predicting learning strategies, task disengagement, peer relationship, and achievement outcome. Contem- 
porary Educational Psychology, 33, 486-512. doi:10.1016/j.cedpsych .2007.08.001

Mendes, W. B., Blascovich, J., Major, B., \& Seery, M. (2001). Challenge and threat responses during downward and upward social comparisons. European Journal of Social Psychology, 31, 477-497. doi:10.1002/ ejsp. 80

Migacheva, K., \& Tropp, L. R. (2013). Learning orientation as a predictor of positive intergroup contact. Group Processes \& Intergroup Relations, $16,426-444$

Mugny, G., Butera, F., \& Falomir, J. M. (2001). Social influence and threat in social comparison between self and source's competence: Relational factors affecting the transmission of knowledge. In F. Butera \& G. Mugny (Eds.), Social influence in social reality (pp. 225-246). Bern, Switzerland: Hogrefe \& Huber.

Mugny, G., \& Carugati, F. (1989). Social representations of intelligence. Cambridge, United Kingdom: Cambridge University Press.

Mugny, G., \& Doise, W. (1978). Socio-cognitive conflict and structure of individual and collective performances. European Journal of Social Psychology, 8, 181-192. doi:10.1002/ejsp.2420080204

Muis, K. R., \& Duffy, M. C. (2013). Epistemic climate and epistemic change: Instruction designed to change students' beliefs and learning strategies and improve achievement. Journal of Educational Psychology, 105, 213-225. doi:10.1037/a0029690

Muller, D., Atzeni, T., \& Butera, F. (2004). Coaction and upward social comparison reduce the illusory conjunction effect: Support for distraction-conflict theory. Journal of Experimental Social Psychology, 40, 659-665. doi:10.1016/j.jesp.2003.12.003

Muller, D., \& Butera, F. (2007). The focusing effect of self-evaluation threat in coaction and social comparison. Journal of Personality and Social Psychology, 93, 194-211. doi:10.1037/0022-3514.93.2.194

Murayama, K., \& Elliot, A. J. (2012). The competition-performance relation: A meta-analytic review and test of the opposing processes model of competition and performance. Psychological Bulletin, 138, 1035-1070. doi: $10.1037 / \mathrm{a} 0028324$

Nesler, M. S., Aguinis, H., Quigley, B. M., Lee, S. J., \& Tedeschi, J. T. (1999). The development and validation of a scale measuring global social power based on French and Raven's power taxonomy. Journal of Applied Social Psychology, 29, 750-769. doi:10.1111/j.1559-1816.1999 .tb02022.x

Newman, R. S., \& Schwager, M. T. (1995). Students' help seeking during problem solving: Effects of grade, goal, and prior achievement. American Educational Research Journal, 32, 352-376. doi:10.3102/ 00028312032002352

Nussbaum, E. M., Sinatra, G. M., \& Owens, M. C. (2012). The two faces of scientific argumentation: Applications to global climate change. In M. S. Khine (Ed.), Perspectives on scientific argumentation (pp. 17-37). Houten, Netherlands: Springer. doi:10.1007/978-94-007-2470-9_2

Ojanen, T., Grönroos, M., \& Salmivalli, C. (2005). An interpersonal circumplex model of children's social goals: Links with peer-reported behavior and sociometric status. Developmental Psychology, 41, 699710. doi:10.1037/0012-1649.41.5.699

Park, E. S., \& Hinsz, V. B. (2006). "Strength and safety in numbers": A theoretical perspective on group influences on approach and avoidance motivation. Motivation and Emotion, 30, 135-142. doi:10.1007/s11031006-9024-y

Patrick, H., Kaplan, A., \& Ryan, A. M. (2011). Positive classroom motivational environments: Convergence between mastery goal structure and classroom social climate. Journal of Educational Psychology, 103, 367382. doi:10.1037/a0023311

Piaget, J. (1952). The origins of intelligence in children. New York, NY: International Universities Press. doi:10.1037/11494-000

Piaget, J. (1985). The equilibration of cognitive structures. Chicago, IL: University of Chicago Press.
Poortvliet, P. M. (2013). Harming others' task-related efforts: The distinct competitive effects of ranking information on performance and mastery goal individuals. Social Psychology, 44, 373-379. doi:10.1027/18649335/a000161

Poortvliet, P. M., Anseel, F., Janssen, O., Van Yperen, N. W., \& Van de Vliert, E. (2012). Perverse effects of other-referenced performance goals in an information exchange context. Journal of Business Ethics, 106, 401-414. doi:10.1007/s10551-011-1005-8

Poortvliet, P. M., \& Darnon, C. (2010). Towards a more social understanding of achievement goals: The interpersonal effects of mastery and performance goals. Current Directions in Psychological Science, 19, 324-328. doi: $10.1177 / 0963721410383246$

Poortvliet, P. M., \& Darnon, C. (2014). Understanding positive attitudes toward helping peers: The role of mastery goals and academic selfefficacy. Self and Identity, 13, 345-363. doi:10.1080/15298868.2013 .832363

Prusak, N., Hershkowitz, R., \& Schwarz, B. B. (2012). From visual reasoning to logical necessity through argumentative design. Educational Studies in Mathematics, 79, 19-40. doi:10.1007/s10649-011-9335-0

Psaltis, C. (2011). The constructive role of gender asymmetry in social interaction: Further evidence. British Journal of Developmental Psychology, 29, 305-312. doi:10.1111/j.2044-835X.2011.02029.x

Psaltis, C., \& Duveen, G. (2006). Social relations and cognitive development: The influence of conversation type and representations of gender. European Journal of Social Psychology, 36, 407-430. doi:10.1002/ejsp .308

Psaltis, C., \& Duveen, G. (2007). Conservation and conversation types: Forms of recognition and cognitive development. British Journal of Developmental Psychology, 25, 79-102. doi:10.1348/026151005X91415

Psaltis, C., Duveen, G., \& Perret-Clermont, A. N. (2009). The social and the psychological: Structure and context in intellectual development. Human Development, 52, 291-312. doi:10.1159/000233261

Pulfrey, C., Buchs, C., \& Butera, F. (2011). Why grades engender performance-avoidance goals: The mediating role of autonomous motivation. Journal of Educational Psychology, 103, 683-700. doi:10.1037/ a0023911

Pulfrey, C., \& Butera, F. (2013). Why neo-liberal values of self-enhancement lead to cheating in higher education: A motivational account. Psychological Science, 24, 2153-2162. doi:10.1177/0956797613487221

Pulfrey, C., Darnon, C., \& Butera, F. (2013). Autonomy and task performance: Explaining the impact of grades on intrinsic motivation. Journal of Educational Psychology, 105, 39-57. doi:10.1037/a0029376

Quiamzade, A. (2007). Imitation and performance in confrontations between competent peers: The role of the representation of the task European Journal of Psychology of Education, 22, 243-258. doi 10.1007/BF03173424

Quiamzade, A., \& Mugny, G. (2001). Social influence dynamics in aptitude tasks. Social Psychology of Education, 4, 311-334. doi:10.1023/A 1011388821962

Quiamzade, A., Mugny, G., \& Darnon, C. (2009). The coordination of problem solving strategies: When low competence sources exert more influence on task processing than high competence sources. British Journal of Social Psychology, 48, 159-182. doi:10.1348/ $014466608 \times 311721$

Quiamzade, A., Mugny, G., Dragulescu, A., \& Buchs, C. (2003). Interaction styles and expert social influence. European Journal of Psychology of Education, 18, 389-404. doi:10.1007/BF03173243

Quiamzade, A., Tomei, A., \& Butera, F. (2000). Informational dependence and informational constraint: Social comparison and social influences in an anagram resolution task. International Review of Social Psychology, $13,123-150$.

Ramani, G. B., Siegler, R. S., \& Hitti, A. (2012). Taking it to the classroom: Number board games as a small group learning activity. 
Journal of Educational Psychology, 104, 661-672. doi:10.1037/ a0028995

Razavi, T. (2001). Self-report measures: An overview of concerns and limitations of questionnaire use in occupational stress research. Southampton, England: School of Management, University of Southampton. Retrieved from http://eprints.soton.ac.uk/35712/1/01-175.pdf?origin= publication_detail

Reyes, M. R., Brackett, M. A., Rivers, S. E., White, M., \& Salovey, P. (2012). Classroom emotional climate, student engagement, and academic achievement. Journal of Educational Psychology, 104, 700-712. doi: $10.1037 / \mathrm{a} 0027268$

Richardson, J. T. (2011). Eta squared and partial eta squared as measures of effect size in educational research. Educational Research Review, 6, 135-147. doi:10.1016/j.edurev.2010.12.001

Rodkin, P. C., Ryan, A. M., Jamison, R., \& Wilson, T. (2013). Social goals, social behavior, and social status in middle childhood. Developmental Psychology, 49, 1139-1150. doi:10.1037/a0029389

Roseth, C. J., Saltarelli, A. J., \& Glass, C. R. (2011). Effects of face-to-face and computer-mediated constructive controversy on social interdependence, motivation, and achievement. Journal of Educational Psychology, 103, 804-820. doi:10.1037/a0024213

Roussel, P., Elliot, A. J., \& Feltman, R. (2011). The influence of achievement goals and social goals on help-seeking from peers in an academic context. Learning and Instruction, 21, 394-402. doi:10.1016/j .learninstruc.2010.05.003

Ryan, A. M., \& Pintrich, P. R. (1997). "Should I ask for help?" The role of motivation and attitudes in adolescents' help seeking in math class. Journal of Educational Psychology, 89, 329-341. doi:10.1037/00220663.89.2.329

Saltarelli, A. J., \& Roseth, C. J. (in press). Effects of synchronicity and belongingness on face-to-face and computer-mediated constructive controversy. Journal of Educational Psychology.

Schoor, C., \& Bannert, M. (2011). Motivation in a computer-supported collaborative learning scenario and its impact on learning activities and knowledge acquisition. Learning and Instruction, 21, 560-573. doi: 10.1016/j.learninstruc.2010.11.002

Senko, C., Hama, H., \& Belmonte, K. (2013). Achievement goals, study strategies, and achievement: A test of the "learning agenda" framework. Learning and Individual Differences, 24, 1-10. doi:10.1016/j.lindif.2012 .11 .003

Senko, C., \& Harackiewicz, J. M. (2005). Regulation of achievement goals: The role of competence feedback. Journal of Educational Psychology, 97, 320-336. doi:10.1037/0022-0663.97.3.320

Senko, C., Hulleman, C. S., \& Harackiewicz, J. M. (2011). Achievement goal theory at the crossroads: Old controversies, current challenges, and new directions. Educational Psychologist, 46, 26-47. doi:10.1080/ 00461520.2011 .538646

Shim, S. S., Cho, Y., \& Wang, C. (2013). Classroom goal structures, social achievement goals, and adjustment in middle school. Learning and Instruction, 23, 69-77. doi:10.1016/j.learninstruc.2012.05.008

Slavin, R. E. (1996). Research on cooperative learning and achievement: What we know, what we need to know. Contemporary Educational Psychology, 21, 43-69. doi:10.1006/ceps.1996.0004

Sommet, N., Darnon, C., Mugny, G., Quiamzade, A., Pulfrey, C., Dompnier, B., \& Butera, F. (2014). Performance goals in conflictual social interactions: Towards the distinction between two modes of relational conflict regulation. British Journal of Social Psychology, 53, $134-153$.

Sommet, N., Pulfrey, C., \& Butera, F. (2013). Did my MD really go to university to learn? Detrimental effects of numerus clausus on selfefficacy, mastery goals and learning. PLOS ONE, 8, e84178. doi:10 .1371/journal.pone. 0084178
Spears, R., \& Lea, M. (1994). Panacea or panopticon? The hidden power in computer-mediated communication. Communication Research, 21 , 427-459. doi:10.1177/009365094021004001

Tammivaara, J. S. (1982). The effects of task structure on beliefs about competence and participation in small groups. Sociology of Education, 55, 212-222. doi:10.2307/2112673

Tanaka, A., Murakami, Y., Okuno, T., \& Yamauchi, H. (2001). Achievement goals, attitudes toward help seeking, and help-seeking behavior in the classroom. Learning and Individual Differences, 13, 23-35. doi 10.1016/S1041-6080(02)00043-2

Tesser, A. (1988). Toward a self-evaluation maintenance model of social behavior. In L. Berkowitz (Ed.), Advances in experimental social psychology (Vol. 21, pp. 181-227). New York, NY: Academic Press. doi:10.1016/S0065-2601(08)60227-0

Thomas, K. W., \& Kilmann, R. H. (1978). Comparison of four instruments measuring conflict behavior. Psychological Reports, 42, 1139-1145. doi:10.2466/pr0.1978.42.3c.1139

Trautwein, U., Lüdtke, O., Marsh, H. W., \& Nagy, G. (2009). Withinschool social comparison: How students perceive the standing of their class predicts academic self-concept. Journal of Educational Psychology, 101, 853-866. doi:10.1037/a0016306

Tsagris, M., Elmatzoglou, I., \& Frangos, C. C. (2012). The assessment of performance of correlation estimates in discrete bivariate distributions using bootstrap methodology. Communications in Statistics-Theory and Methods, 41, 138-152. doi:10.1080/03610926.2010.521281

Valentiner, D. P., Mounts, N. S., Durik, A. M., \& Gier-Lonsway, S. L. (2011). Shyness mindset: Applying mindset theory to the domain of inhibited social behavior. Personality and Individual Differences, 50, 1174-1179. doi:10.1016/j.paid.2011.01.021

Vansteenkiste, M., Mouratidis, A., \& Lens, W. (2010). Detaching reasons from aims: Fair play and well-being in soccer as a function of pursuing performance-approach goals for autonomous or controlling reasons. Journal of Sport \& Exercise Psychology, 32, 217-242.

Van Yperen, N. W. (2006). A novel approach to assessing achievement goals in the context of the $2 \times 2$ framework: Identifying distinct profiles of individuals with different dominant achievement goals. Personality and Social Psychology Bulletin, 32, 1432-1445. doi:10.1177/ 0146167206292093

Van Yperen, N. W., Blaga, M., \& Postmes, T. (2014). A meta-analysis of self-reported achievement goals and nonself-report performance across three achievement domains (work, sports, and education). PloS one, 9, e93594. doi:10.1371/journal.pone.0093594

Van Yperen, N. W., \& Orehek, E. (2013). Achievement goals in the workplace: Conceptualization, prevalence, profiles, and outcomes. Journal of Economic Psychology, 38, 71-79. doi:10.1016/j.joep.2012.08.013

Vygotsky, L. S. (1978). Mind in society. Cambridge, MA: Harvard University Press.

Webb, N. M. (2009). The teacher's role in promoting collaborative dialogue in the classroom. British Journal of Educational Psychology, 79, 1-28. doi:10.1348/000709908X380772

Weisband, S. P., Schneider, S. K., \& Connolly, T. (1995). Computermediated communication and social information: Status salience and status differences. Academy of Management Journal, 38, 1124-1151. doi: $10.2307 / 256623$

Wentzel, K. R. (2005). Peer relationships, motivation, and academic performance at school. In A. J. Elliot \& C. S. Dweck (Eds.), Handbook of competence and motivation (pp. 279-296). New York, NY: Guilford Press.

Whitebread, D., Bingham, S., Grau, V., Pino Pasternak, D., \& Sangster, C. (2007). Development of metacognition and self-regulated learning in young children: Role of collaborative and peer-assisted learning. Journal of Cognitive Education and Psychology, 6, 433-455. doi:10.1891/ 194589507787382043 
Wiggins, J. S. (2003). Paradigms of personality assessment. New York, NY: Guilford Press.

Wu, X., Anderson, R. C., Nguyen-Jahiel, K., \& Miller, B. (2013). Enhancing motivation and engagement through collaborative discussion. Journal of Educational Psychology, 105, 622-632. doi:10.1037/a0032792

Xie, F. C., \& Wei, B. C. (2007). Diagnostics analysis in censored generalized Poisson regression model. Journal of Statistical Computation and Simulation, 77, 695-708. doi:10.1080/10629360600581316

Yamaguchi, R. (2001). Children's learning groups: A study of emergent leadership, dominance, and group effectiveness. Small Group Research, 32, 671-697. doi:10.1177/104649640103200601

Yzerbyt, V. Y., Muller, D., \& Judd, C. M. (2004). Adjusting researchers' approach to adjustment: On the use of covariates when testing interac- tions. Journal of Experimental Social Psychology, 40, 424-431. doi: 10.1016/j.jesp.2003.10.001

Zweig, D., \& Webster, J. (2004). What are we measuring? An examination of the relationships between the Big-Five personality traits, goal orientation, and performance intentions. Personality and Individual Differences, 36, 1693-1708. doi:10.1016/j.paid.2003.07.010

Received December 19, 2013

Revision received April 30, 2014

Accepted May 12, 2014

\section{E-Mail Notification of Your Latest Issue Online!}

Would you like to know when the next issue of your favorite APA journal will be available online? This service is now available to you. Sign up at http://notify.apa.org/ and you will be notified by e-mail when issues of interest to you become available! 